\title{
Cellular and Molecular Mechanisms Involved in Neuroinflammation after Acute Traumatic Spinal Cord Injury
}

\author{
Noushin Gashmardi ${ }^{1}$, Mohammad Amin Edalatmanesh ${ }^{2 *}$ \\ ${ }^{1}$ Department of Basic Science, Farhangian University, Bushehr, Iran \\ ${ }^{2}$ Department of Physiology, Faculty of Sciences, Shiraz Branch, Islamic Azad University, Shiraz, Iran
}

\section{Article Info:}

\section{A BSTRACT}

Introduction: Spinal cord injury (SCI) following traumatic events is associated with the limited therapeutic options and sever complications, which can be partly due to inflammatory response. Therefore, this study aims to explore the role of inflammation in spinal cord injury. The findings showed that the pathological conditions of nervous system lead to activation of microglia, astrocyte, neutrophil, and macrophages. It is also may be mediated by glial and lead to neuronal injury and death through production of proinflammatory factors, such as cytokines (key factors in the onset, progression and suppression of inflammation) and chemokines. Inflammation is a major component of spinal cord injury; although it is possible that inflammation has beneficial effects, such as phagocytosis of apoptotic cells and pathogens clearance. However, this could contribute to spreading, amplifying, and chronicity of tissue damage, via production of neurotoxic factors. Conclusion: It seems that inflammation has a major role in the injured spinal cord. Identifying effective cells in the inflammatory responses as well as their numbers, nature of their actions, and types of released inflammatory factors, along with the discovery of appropriate coping strategies against them, will increase the hope to repair spinal cord injuries in future.

\section{Key words:}

1. Spinal Cord Injuries

2. Inflammation

3. Astrocytes

4. Cytokines

5. Chemokines

*Corresponding Author: Mohammad Amin Edalatmanesh

E-mail: amin.edalatmanesh@gmail.com 


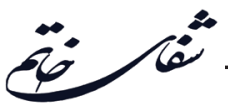

مكانيسمهاى سلولى و مولكولى در تير در التهاب عصبى به دنبال ضايعات نخاعى حاد ترومايى

\author{
نوشين كشمردى'، محمدامين عدالت منش ب" \\ 'اكروه علوم يايه، دانشخاه فرهنَّيان، بوشهر، ايران

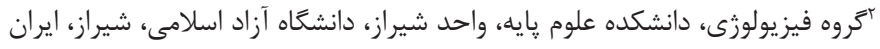

\title{
| اطلاعات مقاله:
}

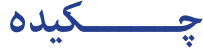

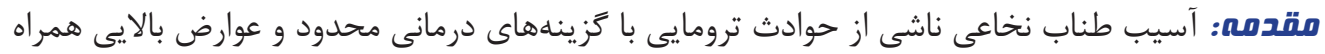

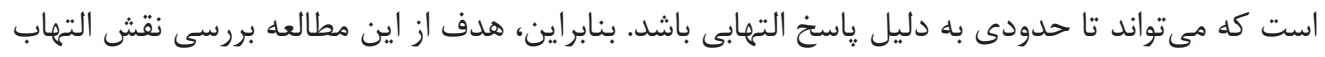

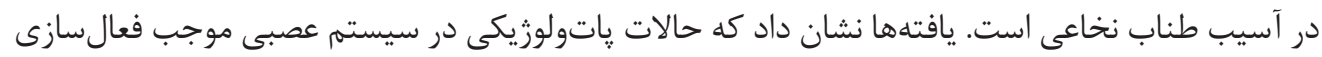

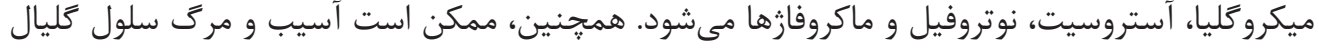

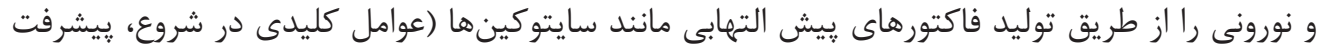

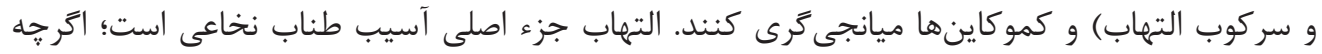

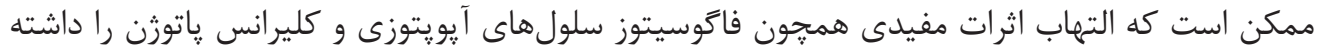

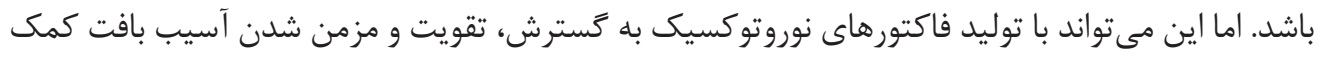

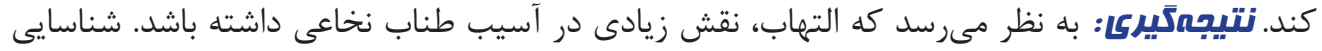

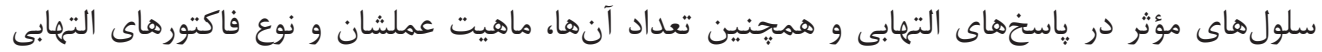

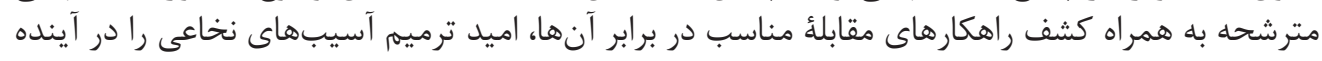

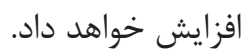

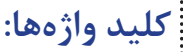

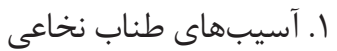

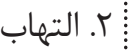

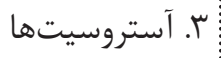

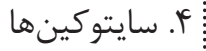

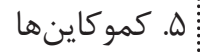

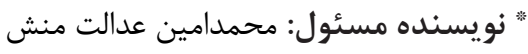
آدرس الكترونيكى: 


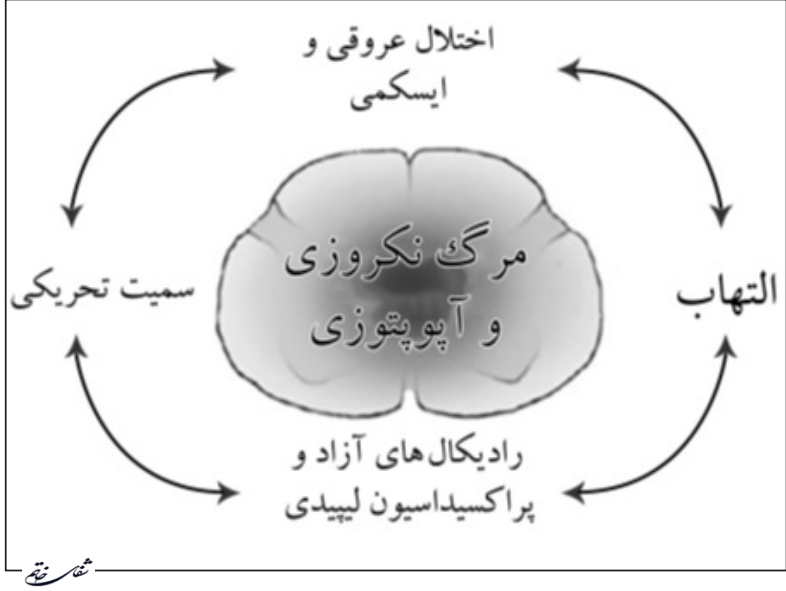

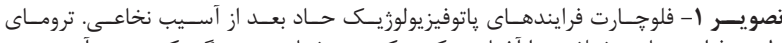

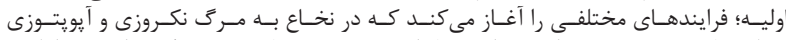

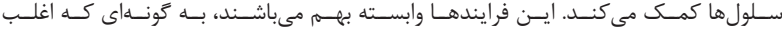

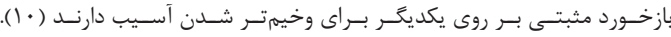

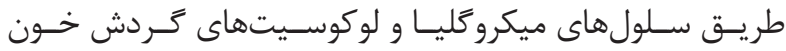

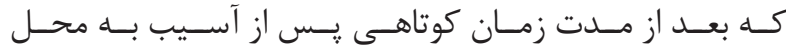

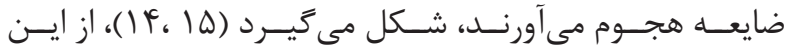

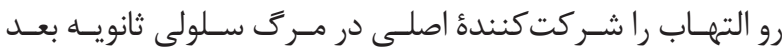

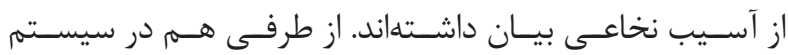

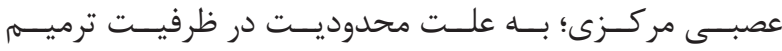

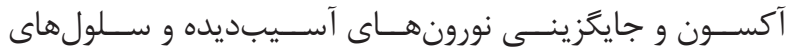

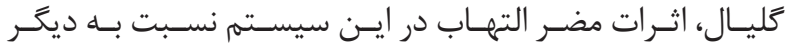

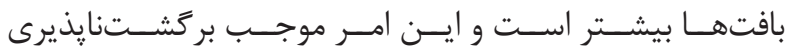

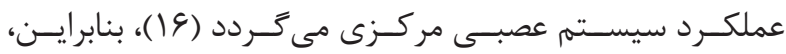

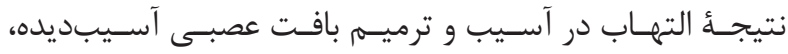

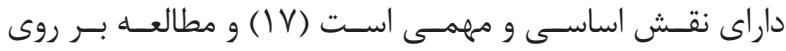

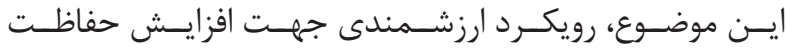

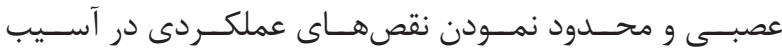

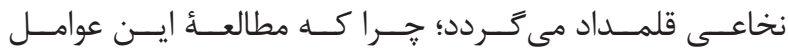

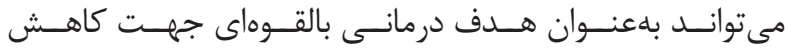

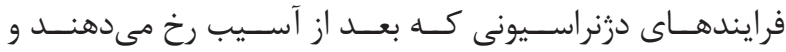

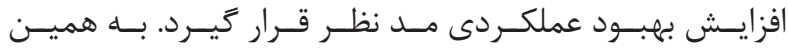

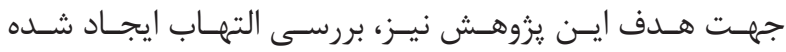

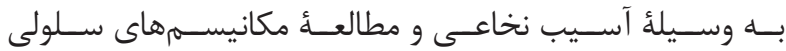

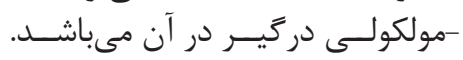

مواد و روشها

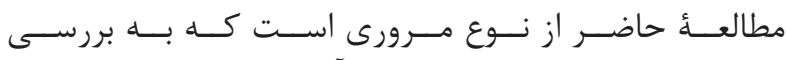

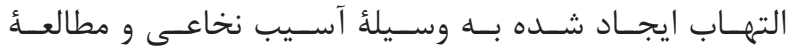

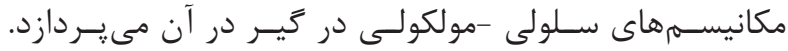

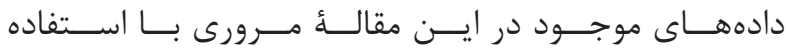

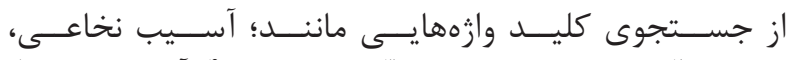

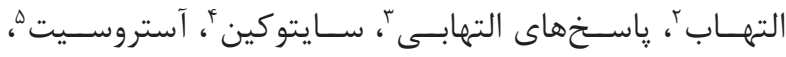

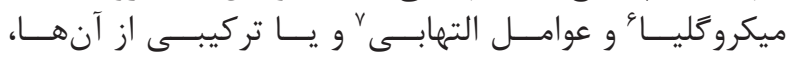

${ }^{1}$ Spinal cord injury

${ }^{2}$ Inflammation

${ }^{3}$ Inflammatory response

${ }^{4}$ Cytokine
مقدمه

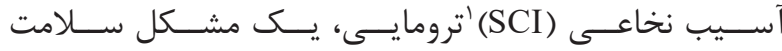

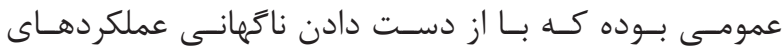

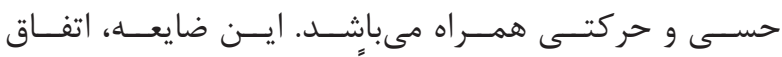

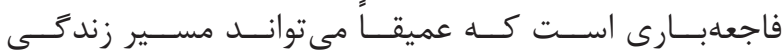

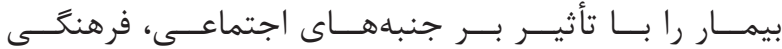

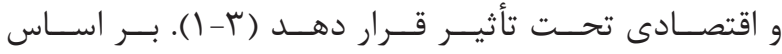

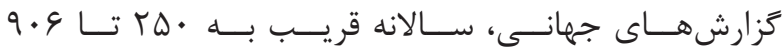

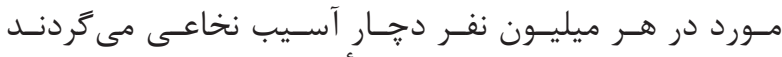

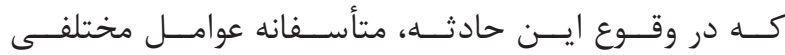

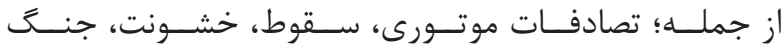

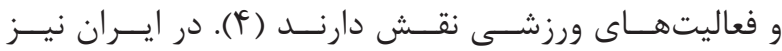

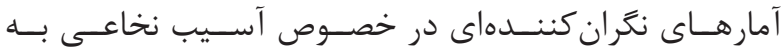

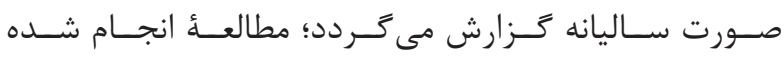

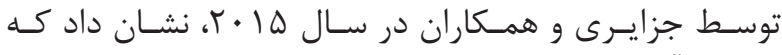

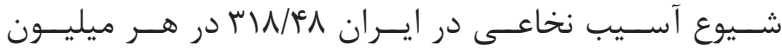

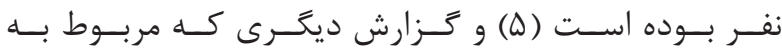

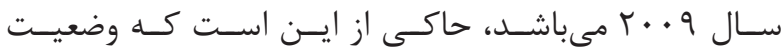

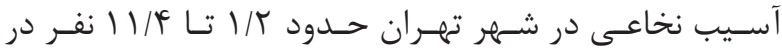

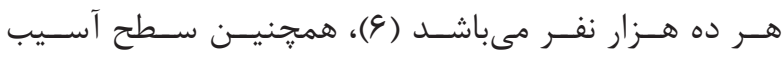

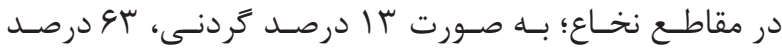

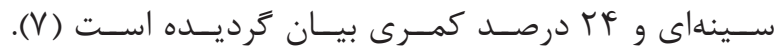

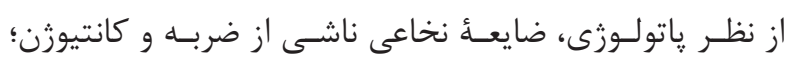

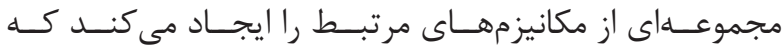

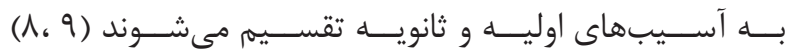

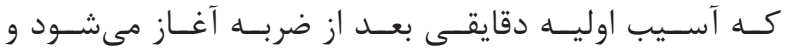

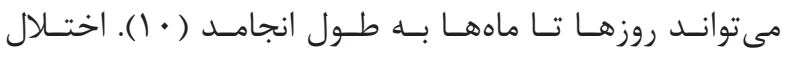

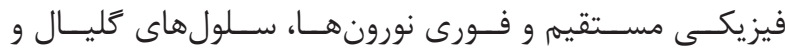

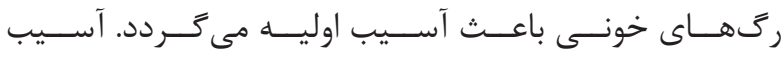

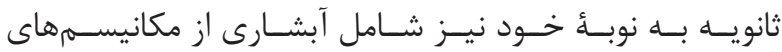

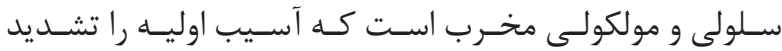

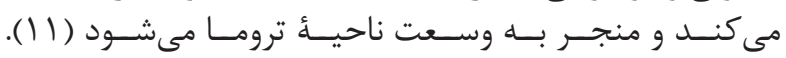

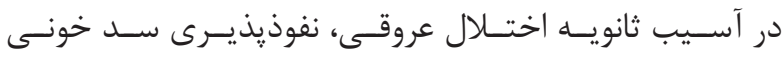

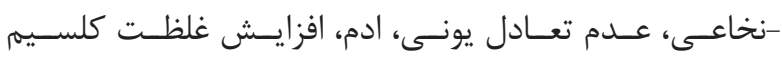

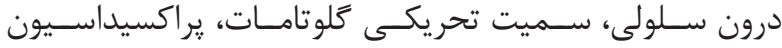

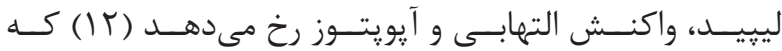

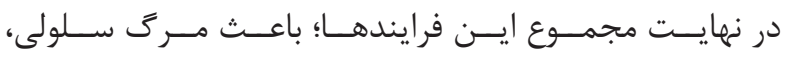

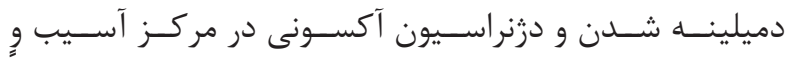

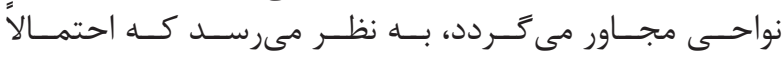

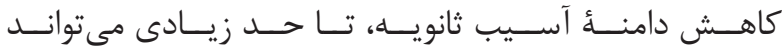

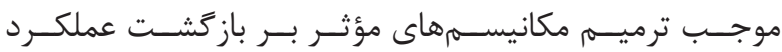

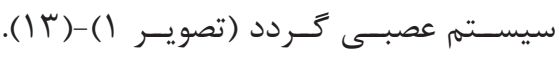

شـايان ذكـر اسـت كـه در آسـيب نخاعى، واكنـش التهابـى از

\footnotetext{
${ }^{5}$ Astrocyte

${ }^{6}$ Microglia

${ }^{7}$ Inflammatory factors
} 


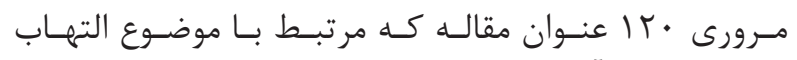

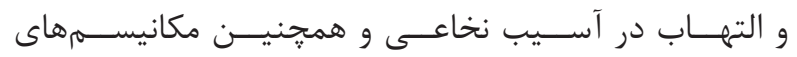

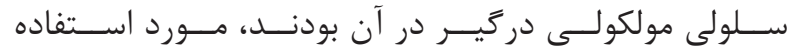

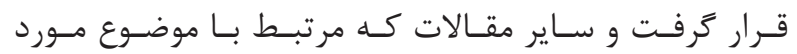

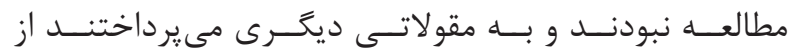

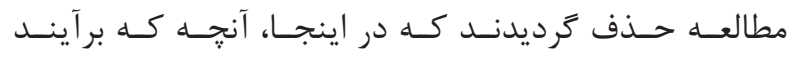

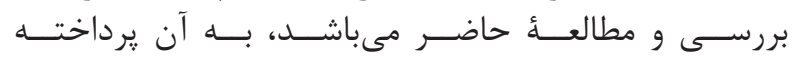

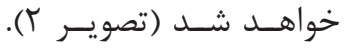

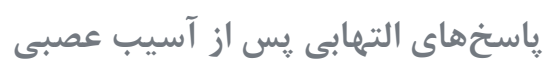

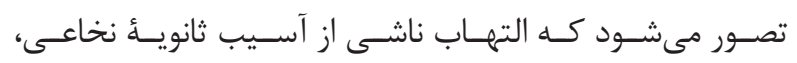

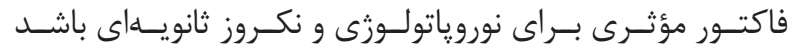

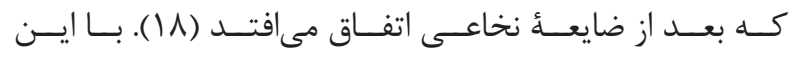

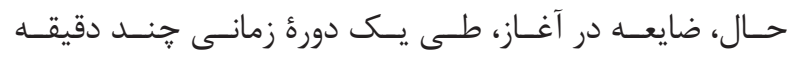

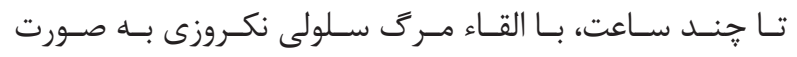

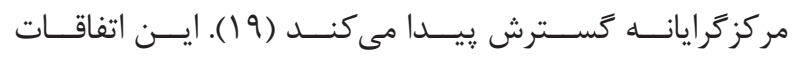

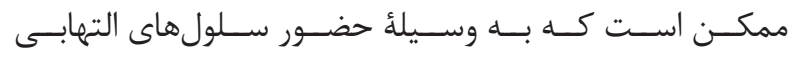

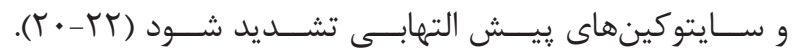

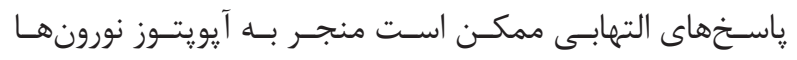

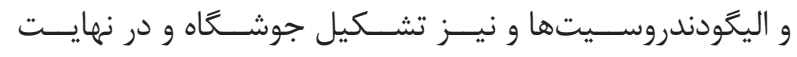

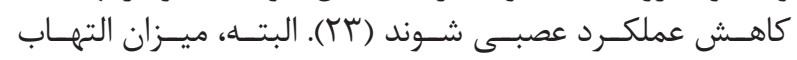

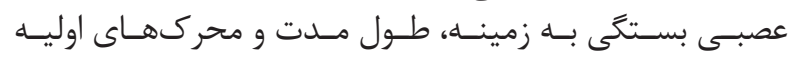

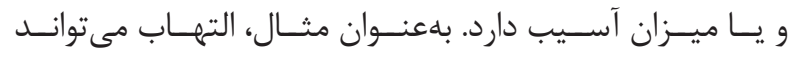

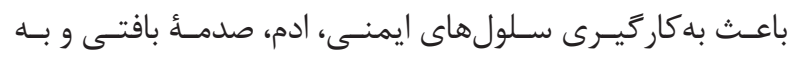

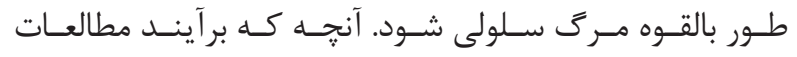

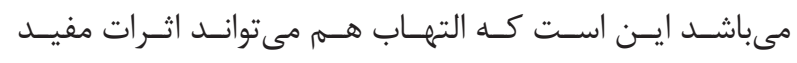

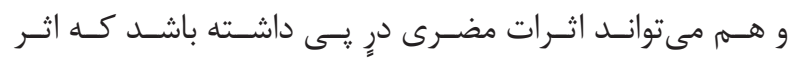

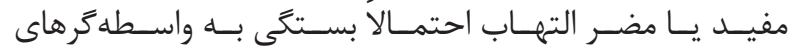

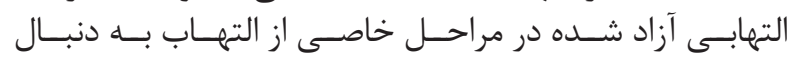

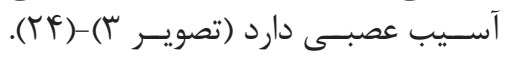

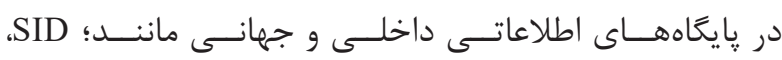
Scopus ، Elsevier.Springer ،Google Scholar ،PubMed

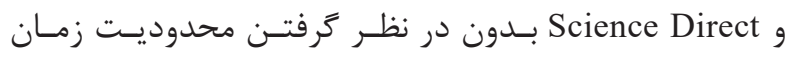

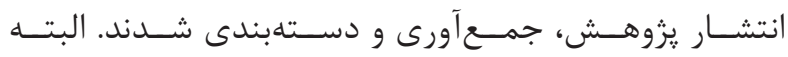

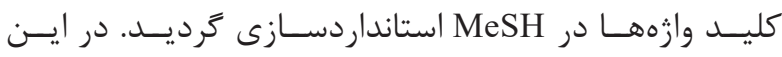

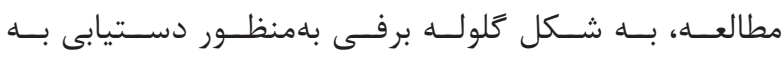

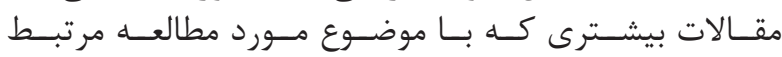

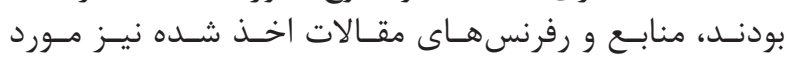

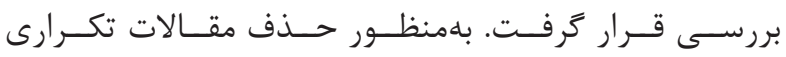

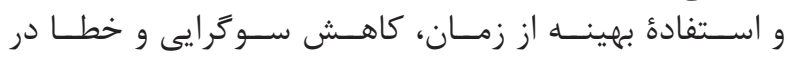

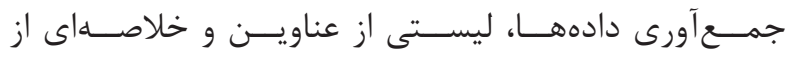

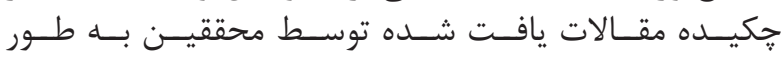

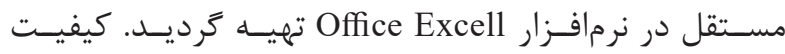

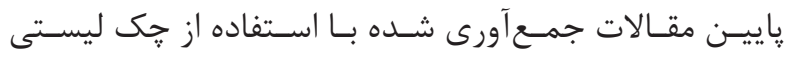

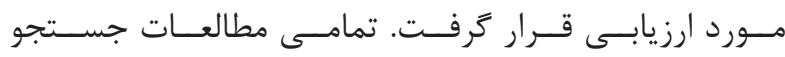

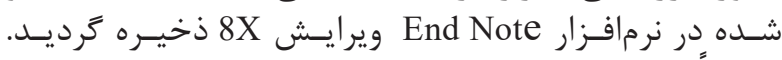

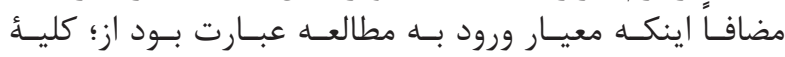

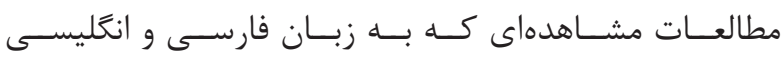

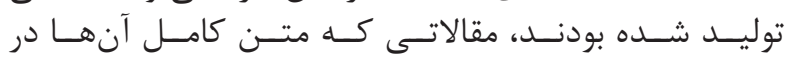

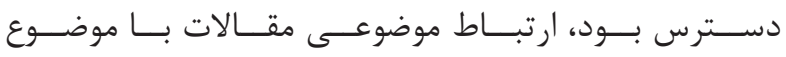

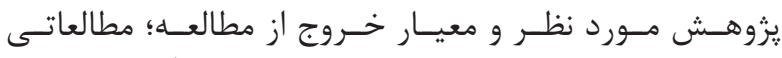

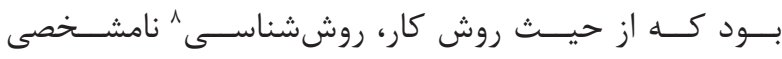

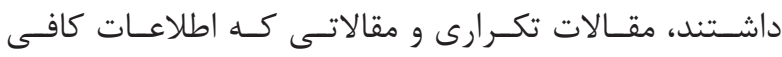

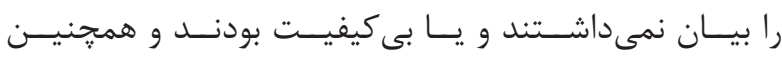

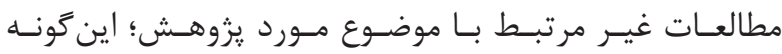

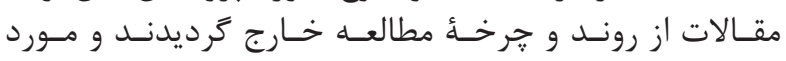

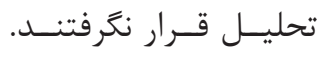

يافته ها

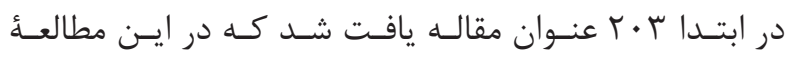

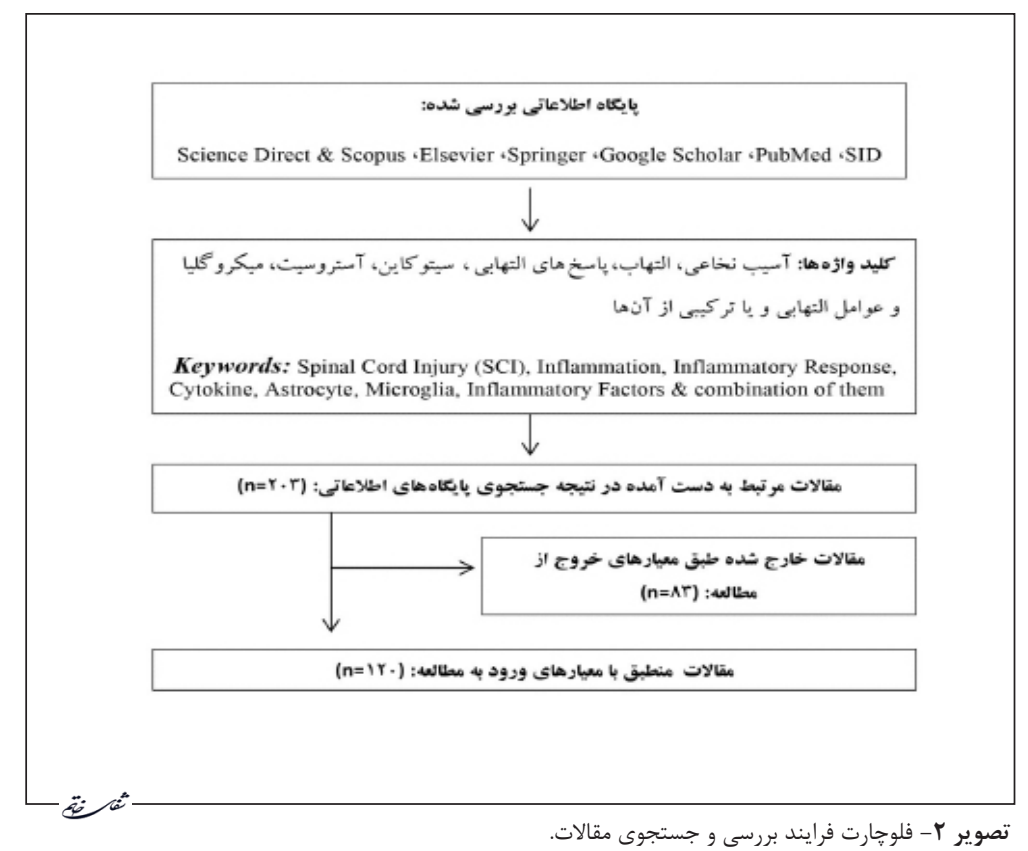

${ }^{8}$ Methodology 


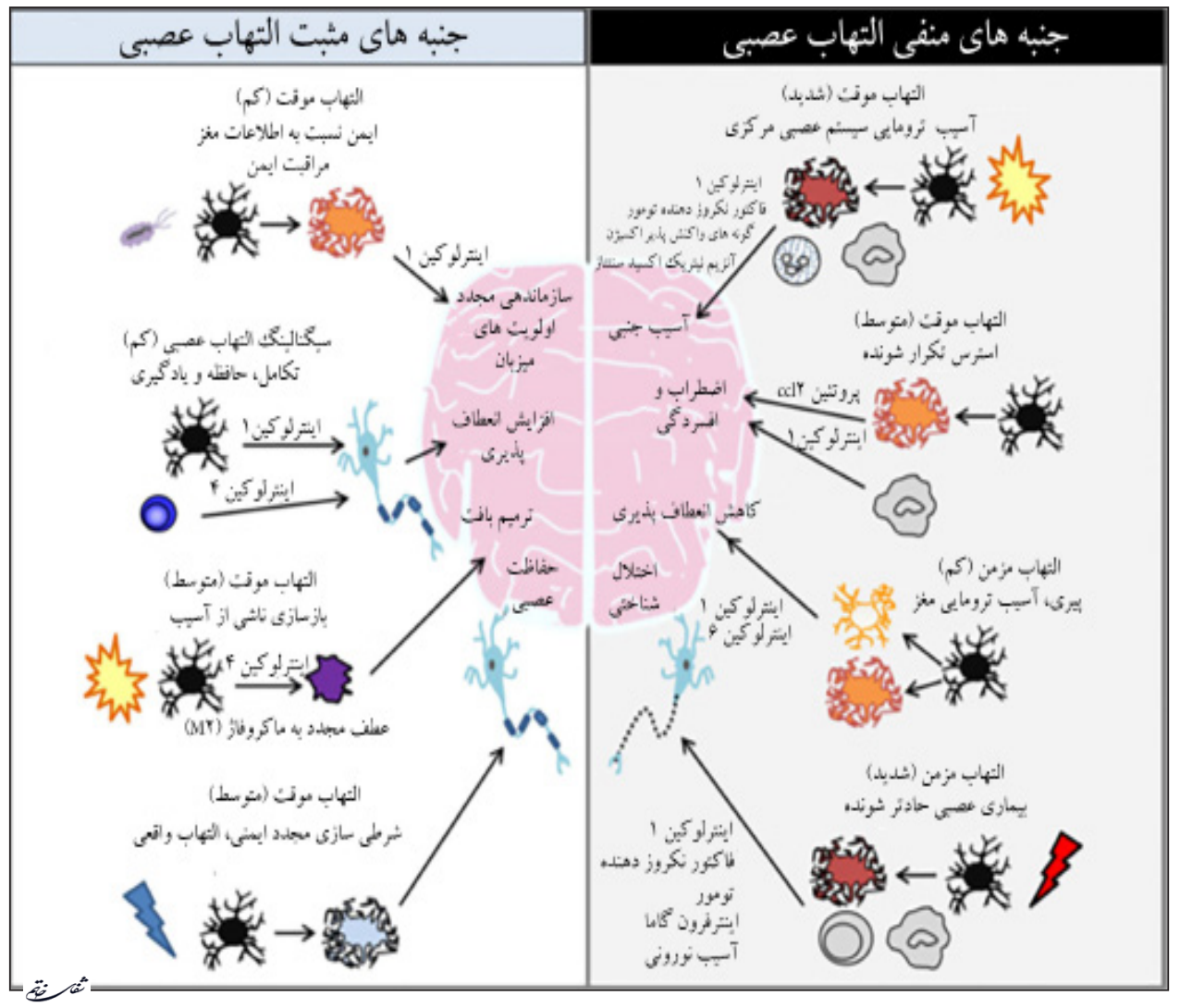

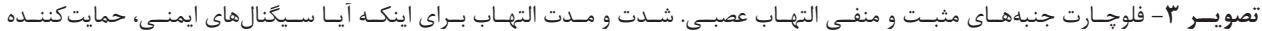

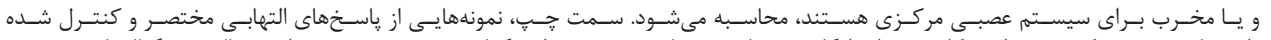

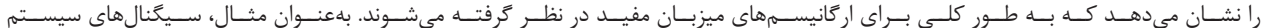

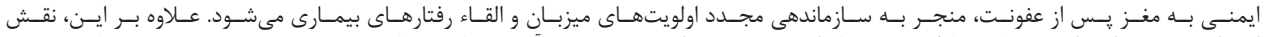

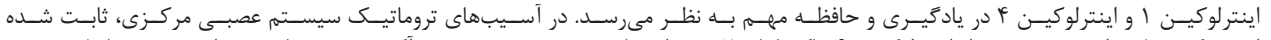

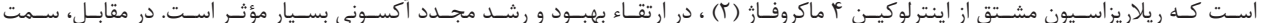

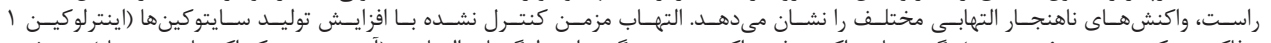

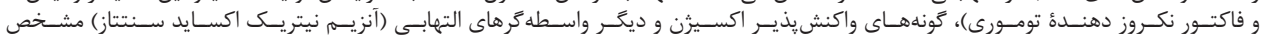

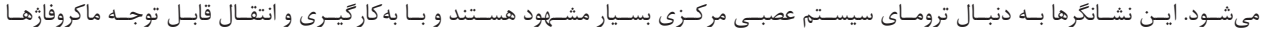

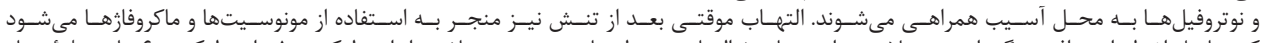

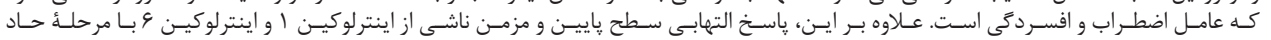

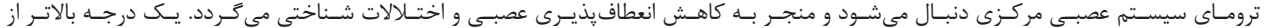

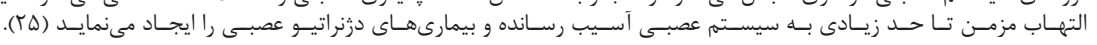

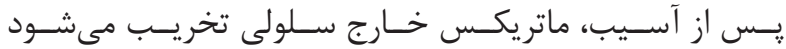

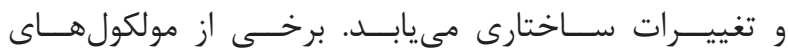

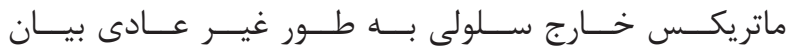

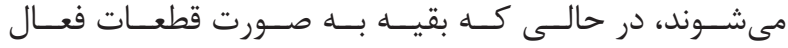

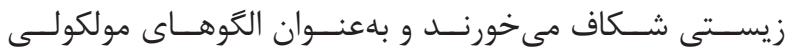

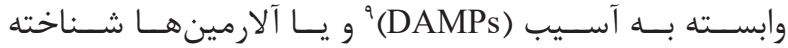

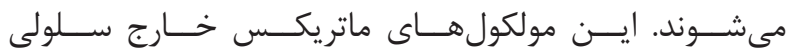

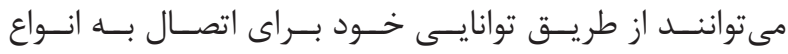

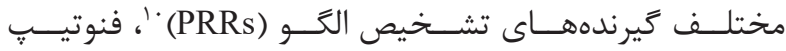

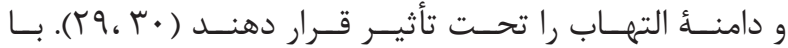

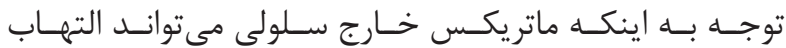

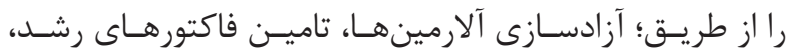

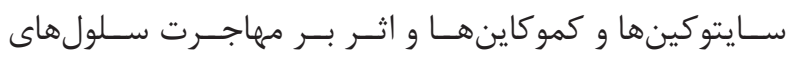

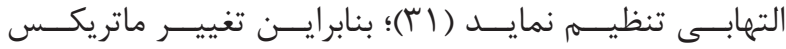

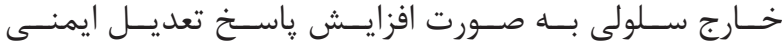

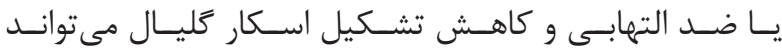

عوامل ايجاد كنندة التهاب بعد از آسيب نخاعى

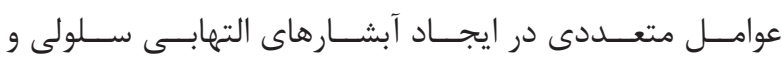

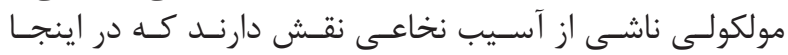

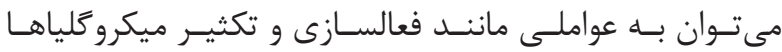

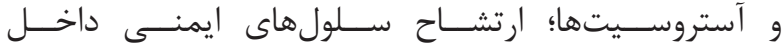

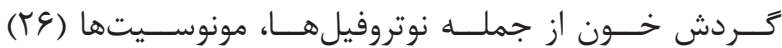

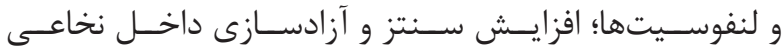

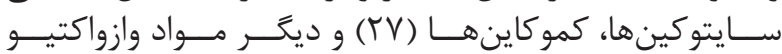

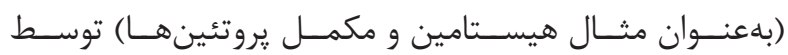

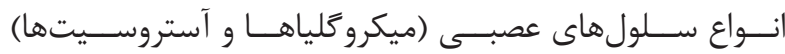

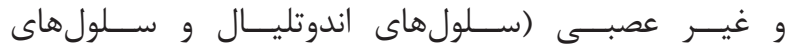

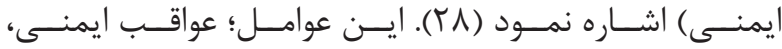

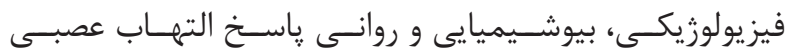

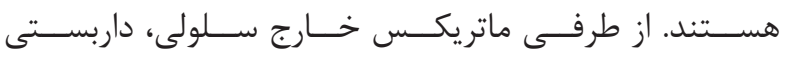

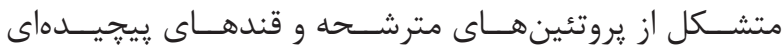

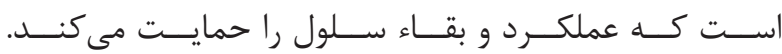

${ }^{9}$ Damage-associated molecular patterns

${ }^{10}$ Pattern recognition receptors 


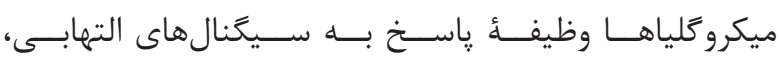

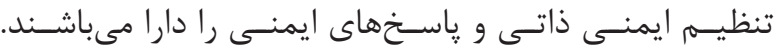

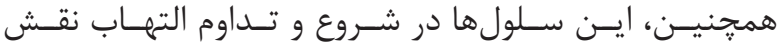

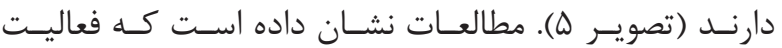

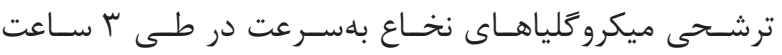

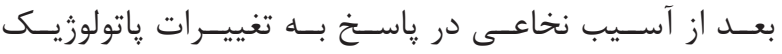

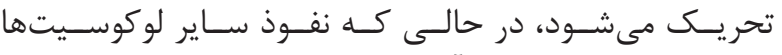

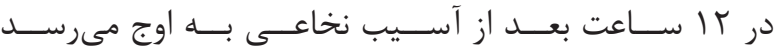

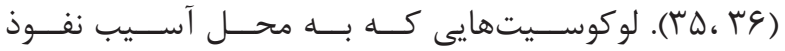

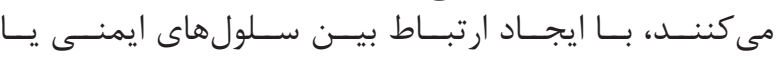

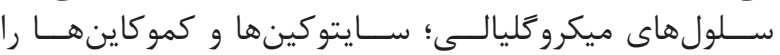

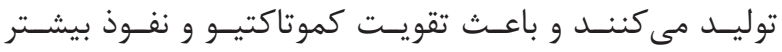

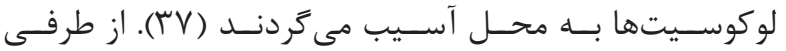

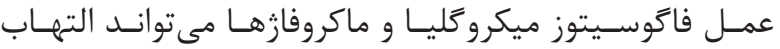

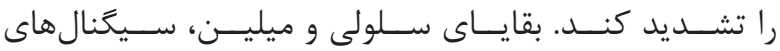

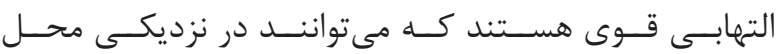

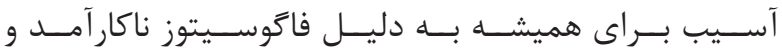

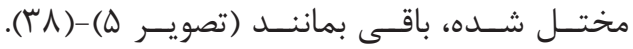

آستروســيتهاى بالـــغ نيــز در التهـــاب عصبــى بـــهـ دنبــالٍ

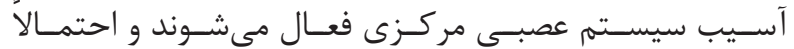

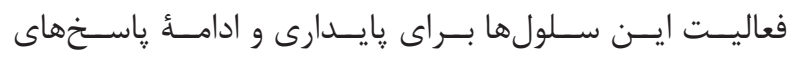

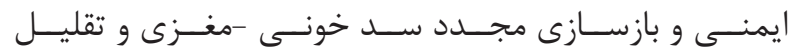

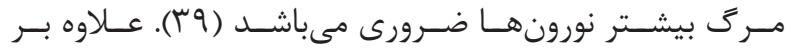

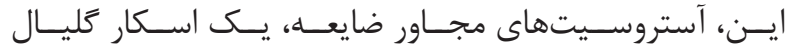

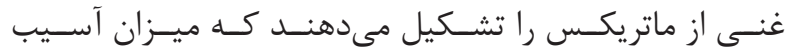

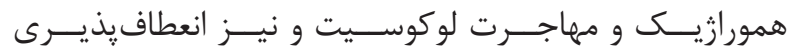

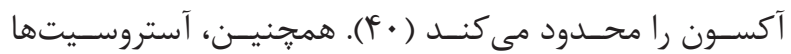

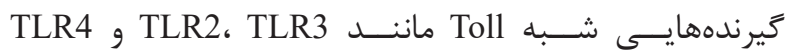

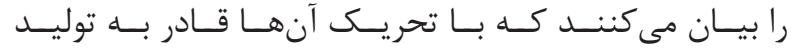

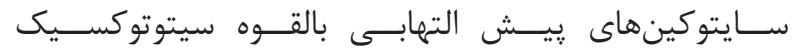

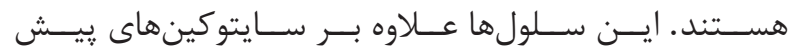

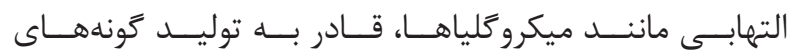

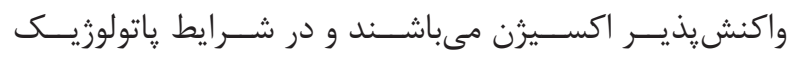

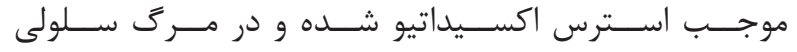

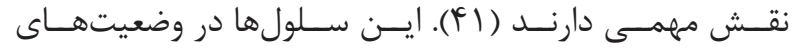

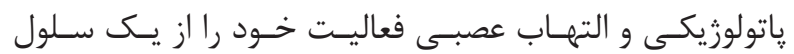

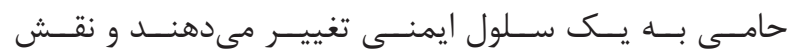

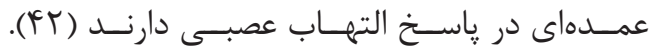

$$
\text { منبع و نقش سايتوكينها و كموكاينها }
$$

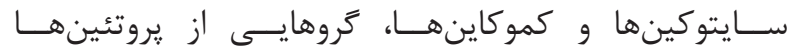

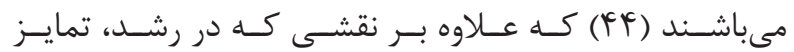

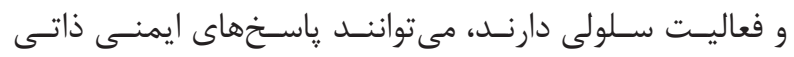

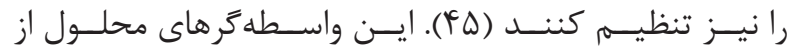

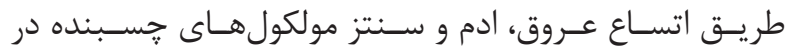

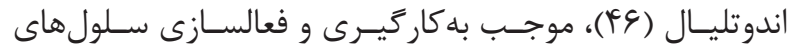

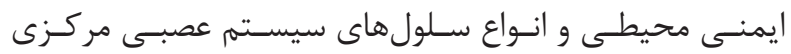

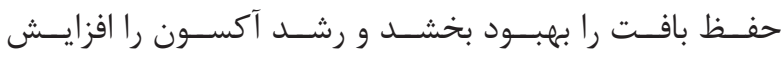

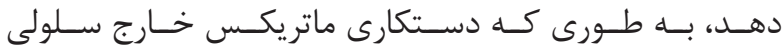

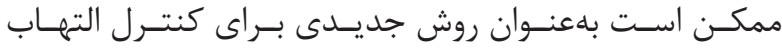

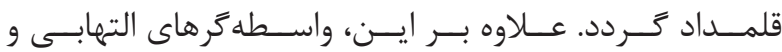

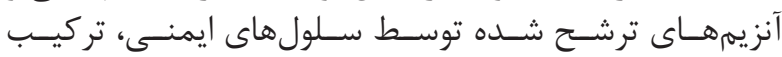

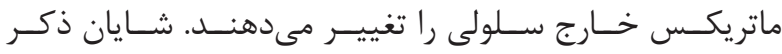

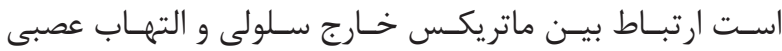

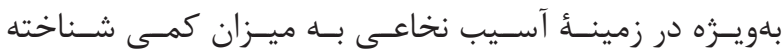

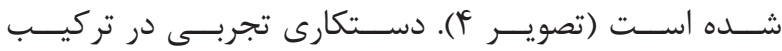

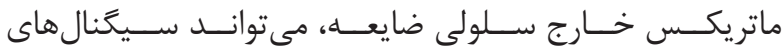

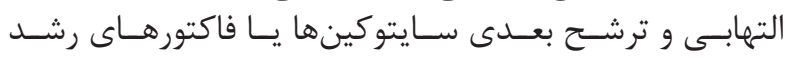

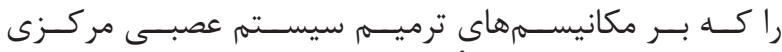

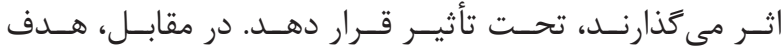

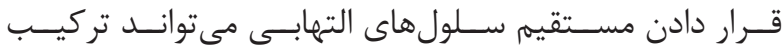

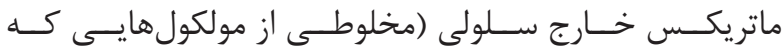

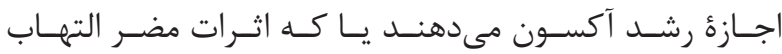

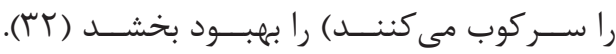

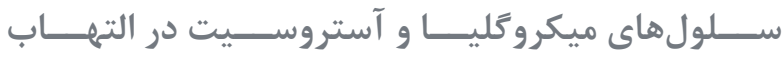

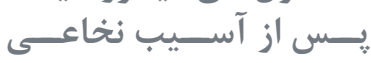

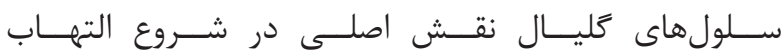

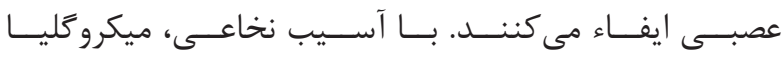

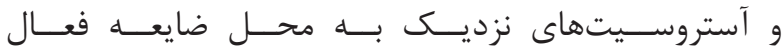

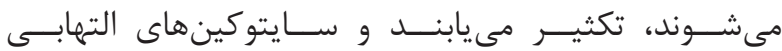

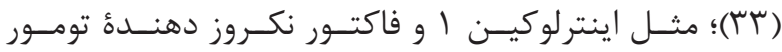
آلفــا (TNF-

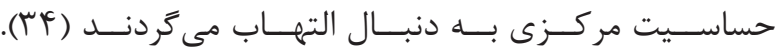

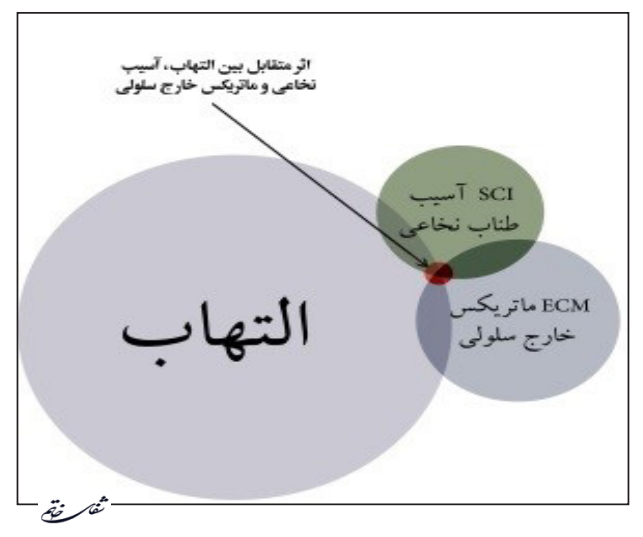

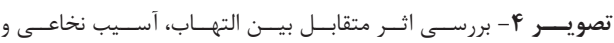

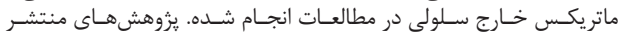

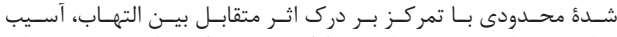

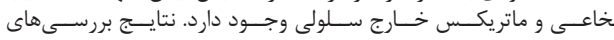

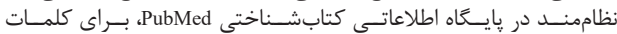

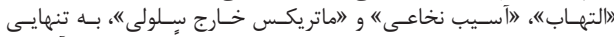

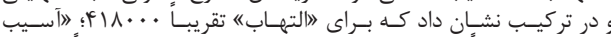

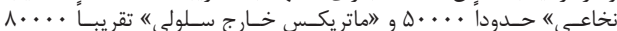

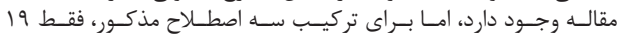

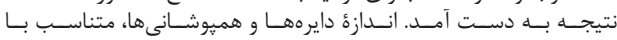

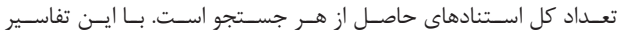

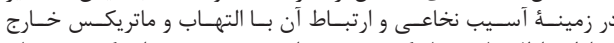

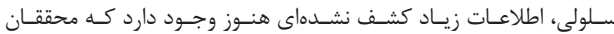

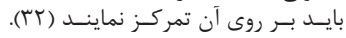




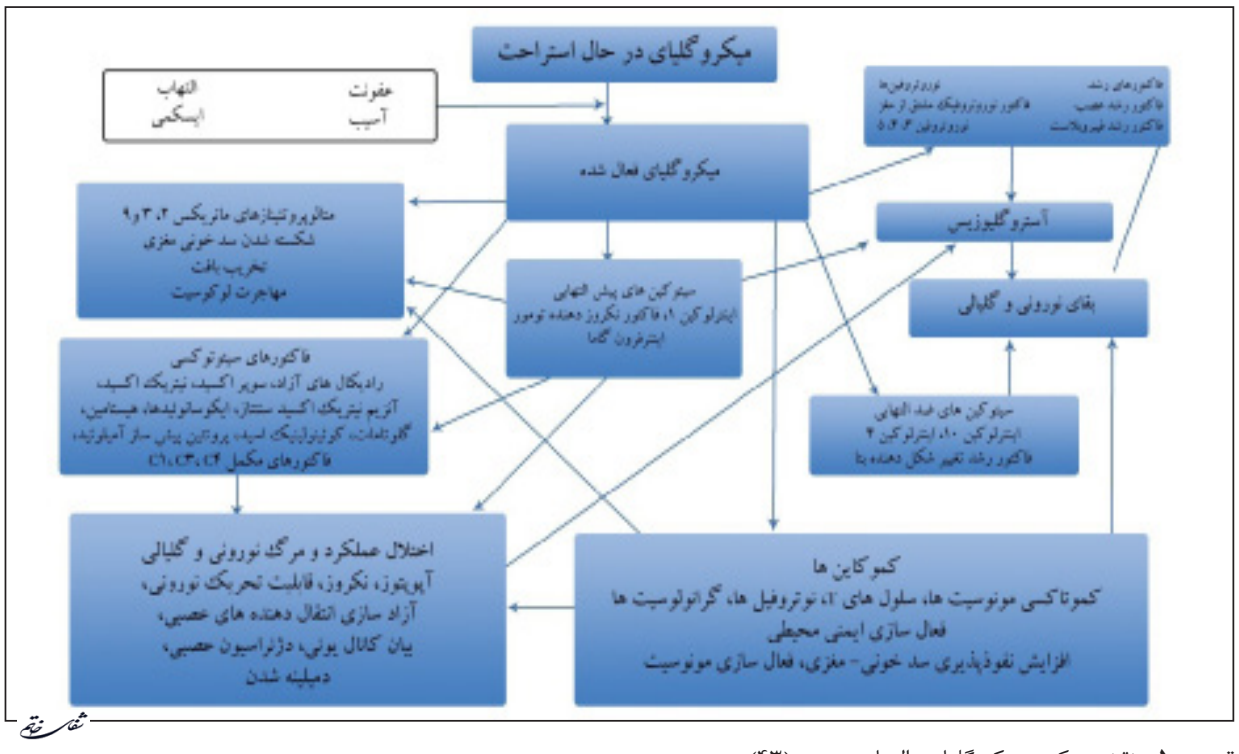

تصوير ه- نقش مركزى ميكروكليا در التهاب عصبى (بَ).

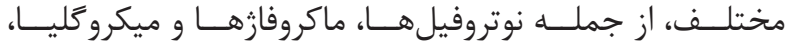

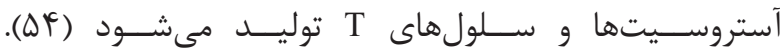

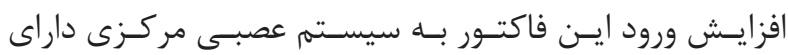

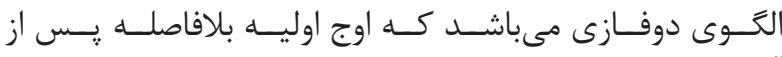

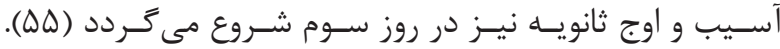

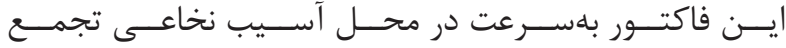

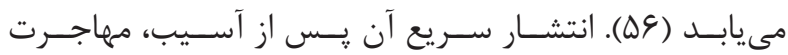

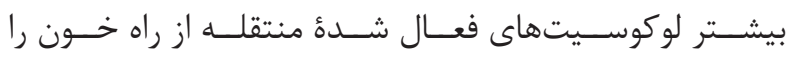

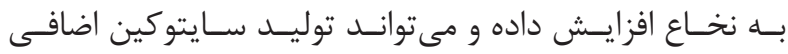

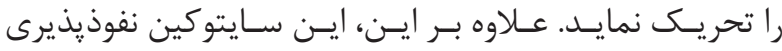

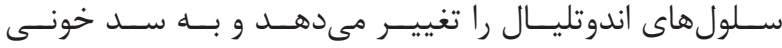

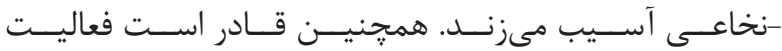

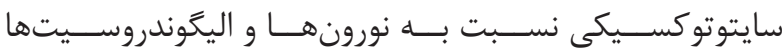

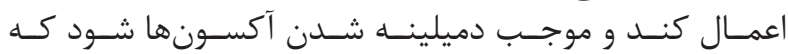

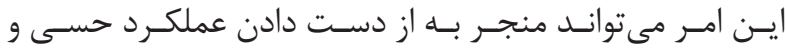

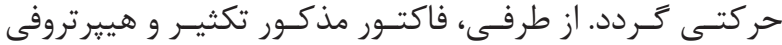

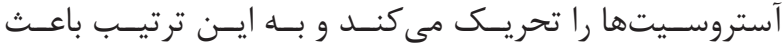

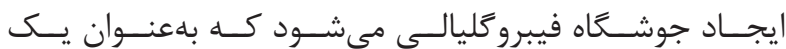

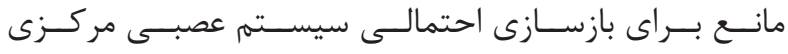

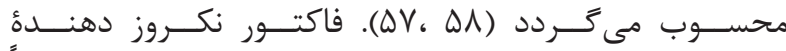

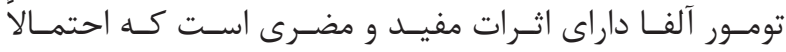

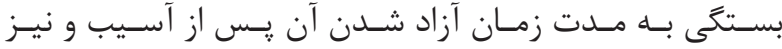

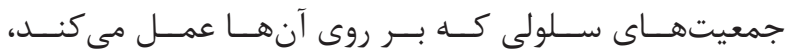

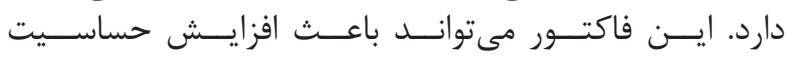

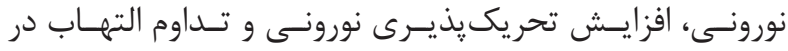

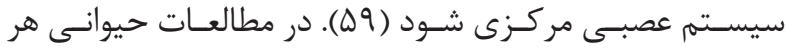

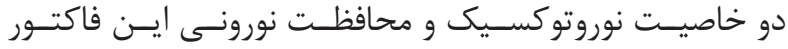

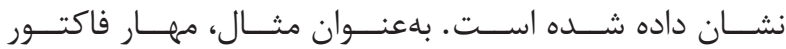

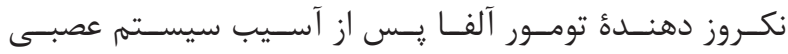

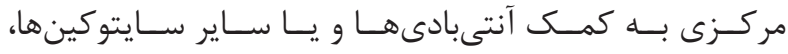

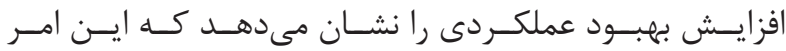

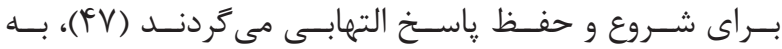

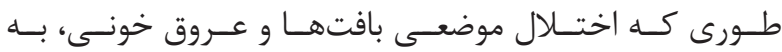

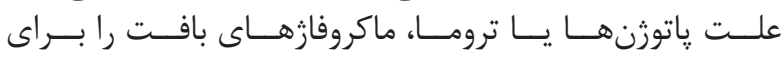

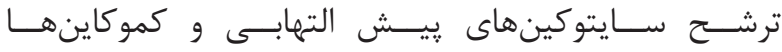

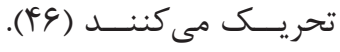

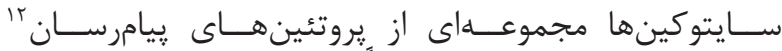

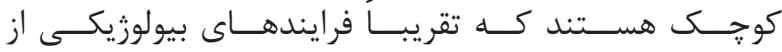

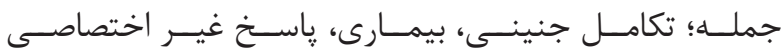

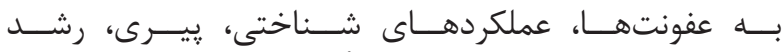

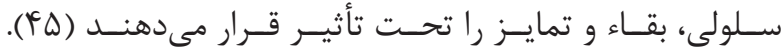

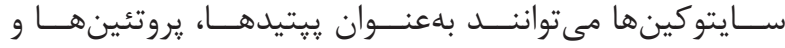

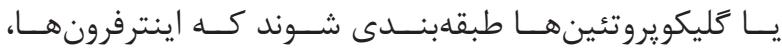

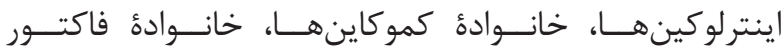

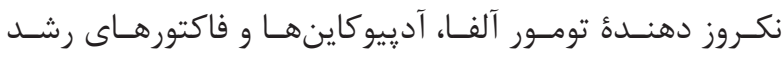

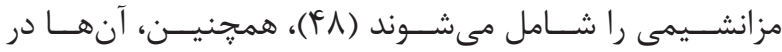

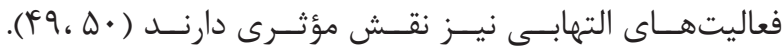

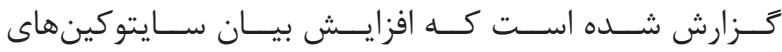

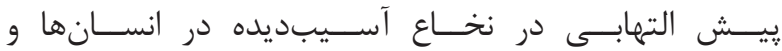

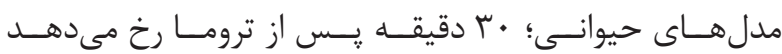

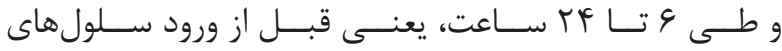

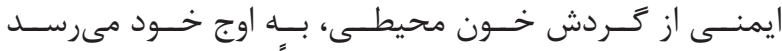

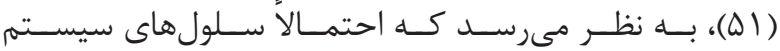

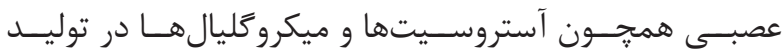

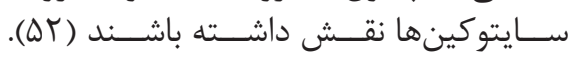

مشـاهده شـده اسـت كـه در فاز حـاد آسـيب نخاعسى، تغييرات

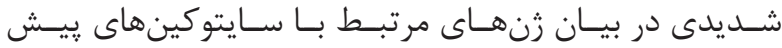

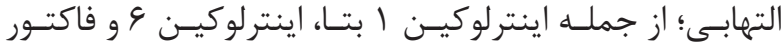

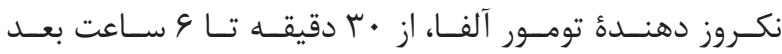

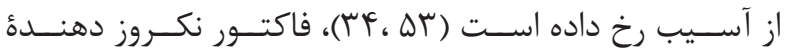

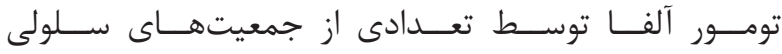




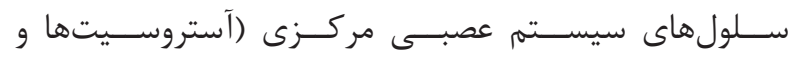

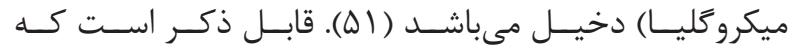

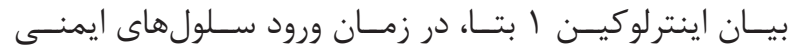

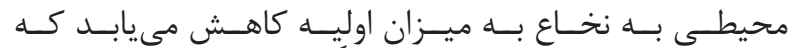

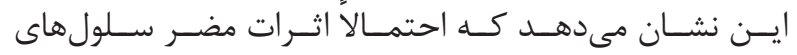

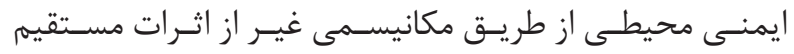

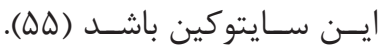

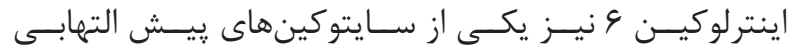

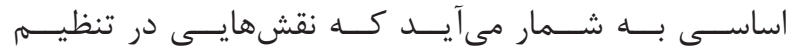

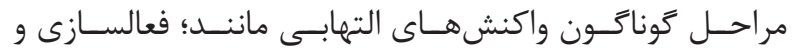

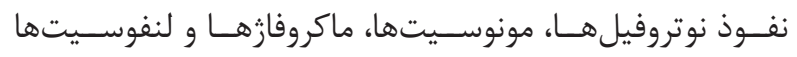

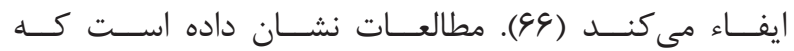

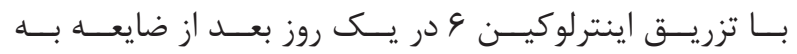

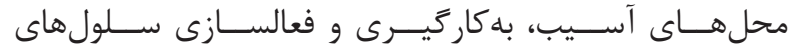

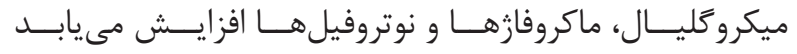

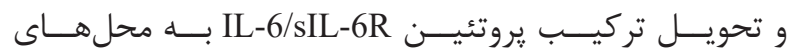

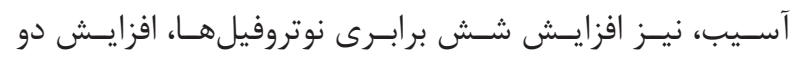

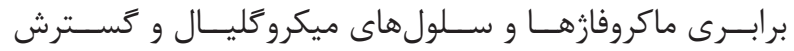

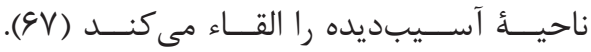

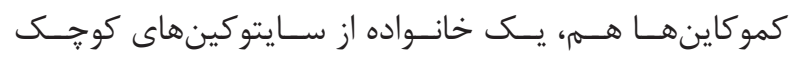

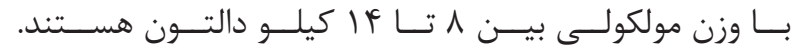

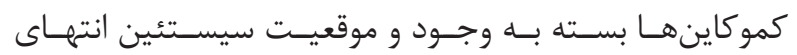

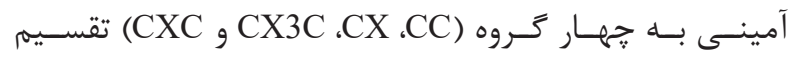
مى

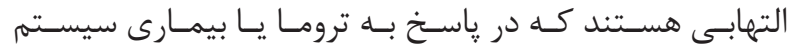

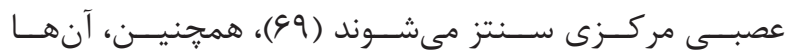

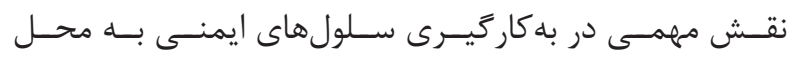

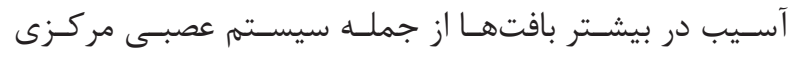

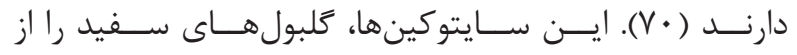

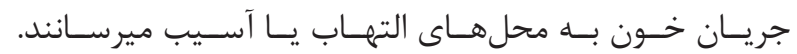

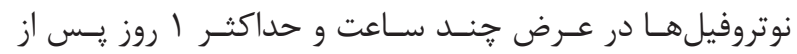

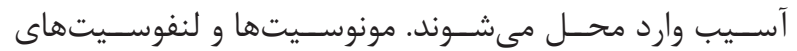

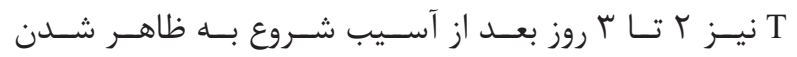

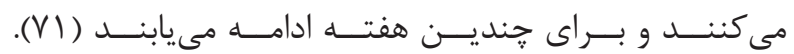

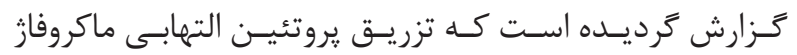

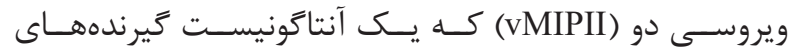

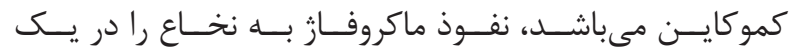

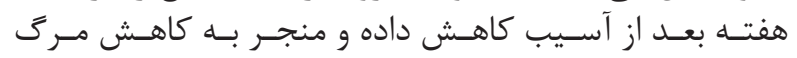

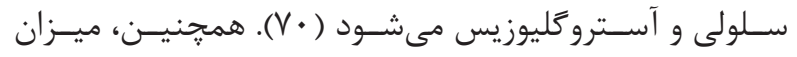

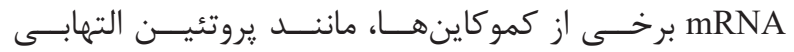

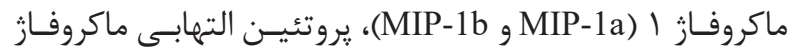

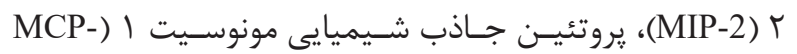

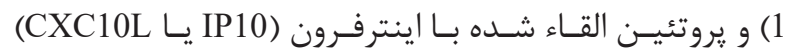

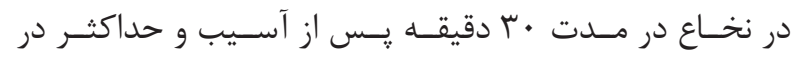

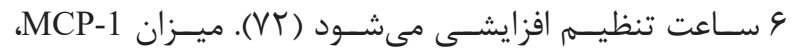
MIP-1a

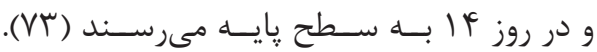

نقـش سايتوتوكسـيك آن را تاييـد مىنمايسـ ( • (؟). در مقابـل،

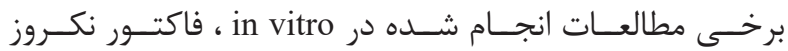

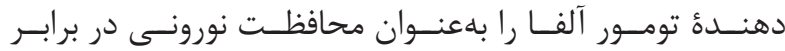

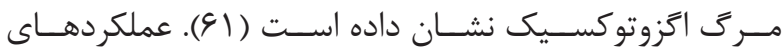

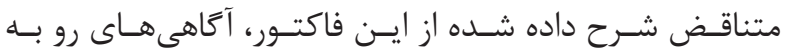

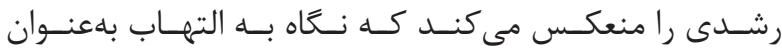

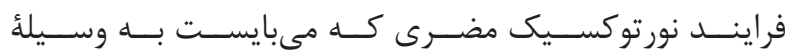

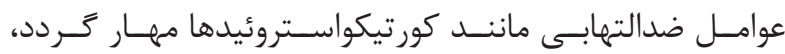

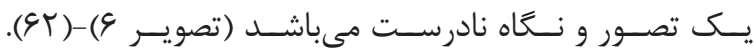

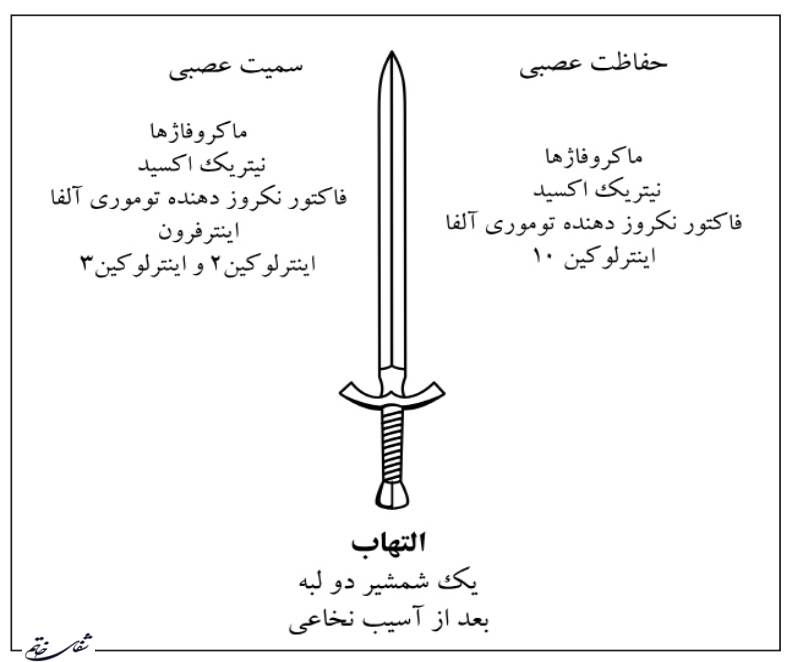

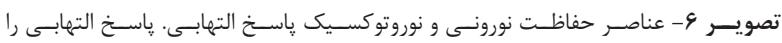

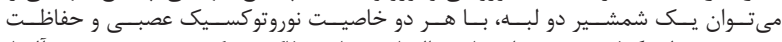

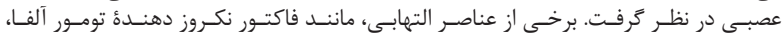

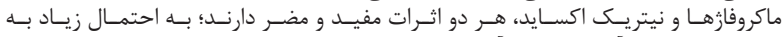

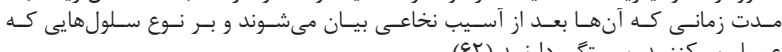

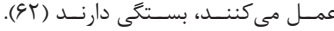

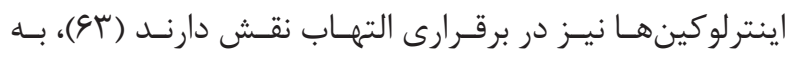

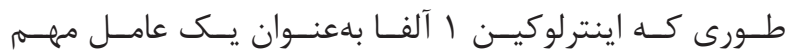

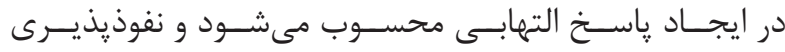

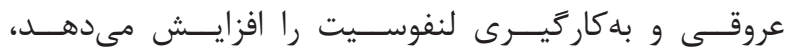

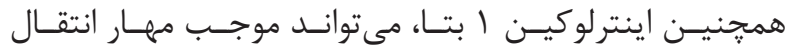

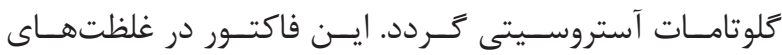

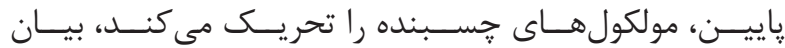

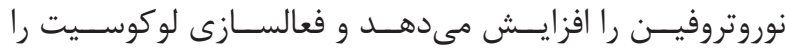

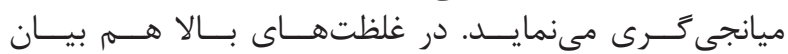

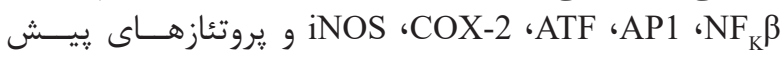

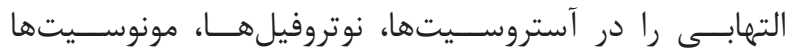

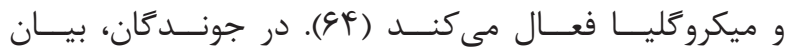

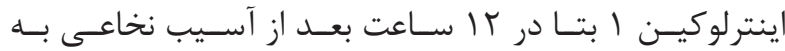

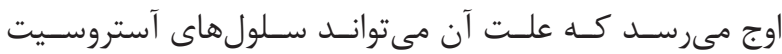

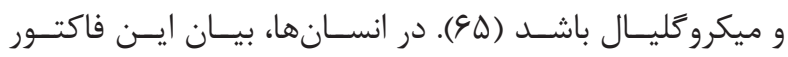

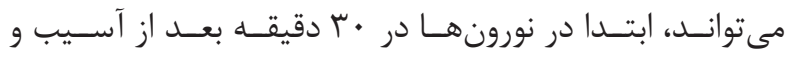

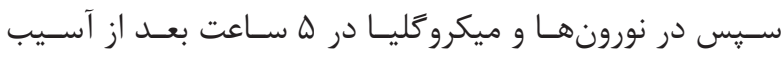

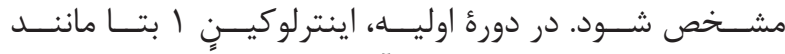

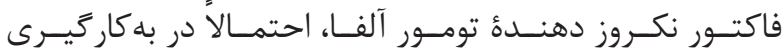

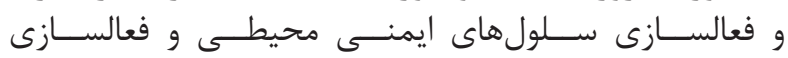




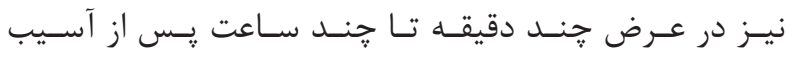

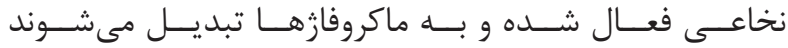

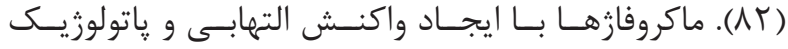

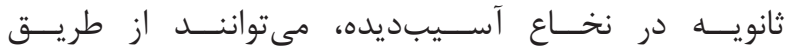

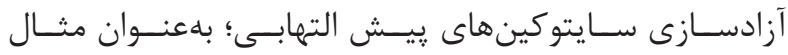

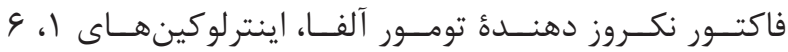

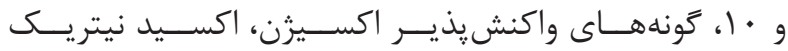

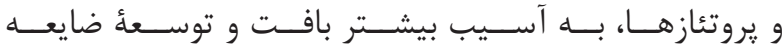

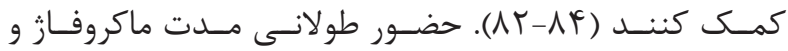

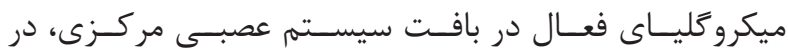

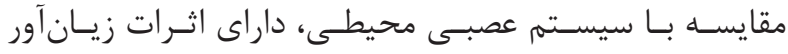

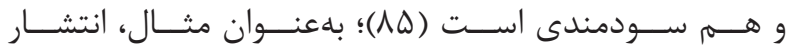

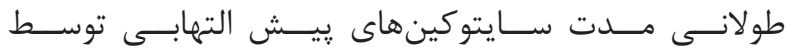

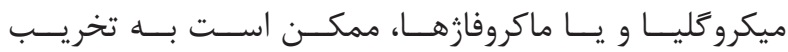

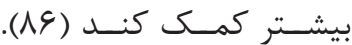

لنفوسيت T و لنفوسيت B در التهاب نخاعى

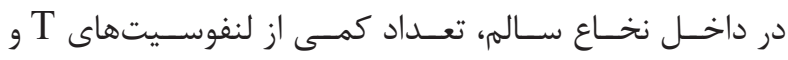

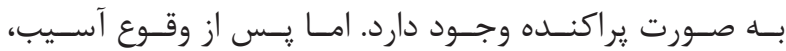

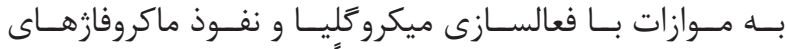

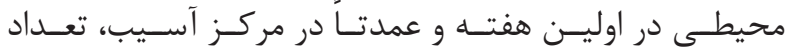

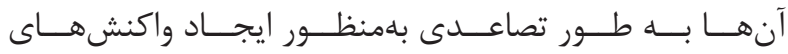

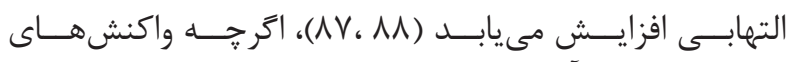

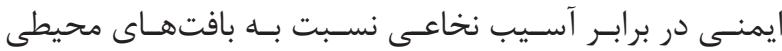

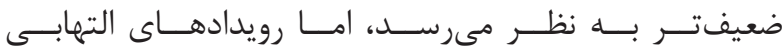

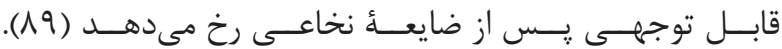

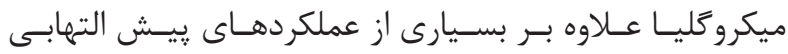

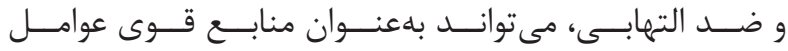

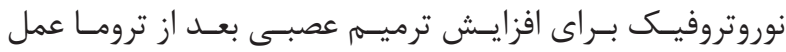

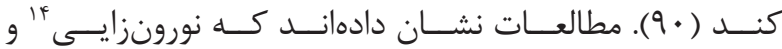

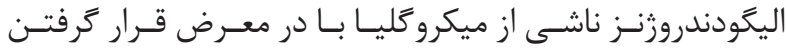

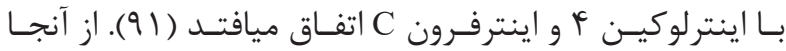

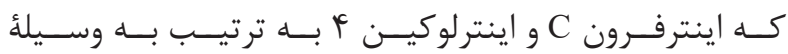

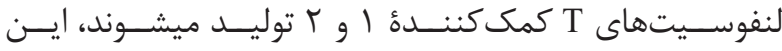

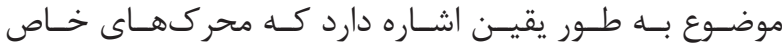

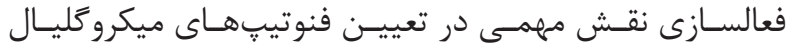

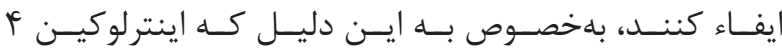

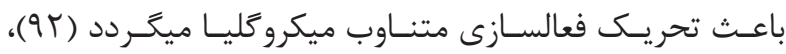

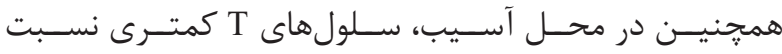

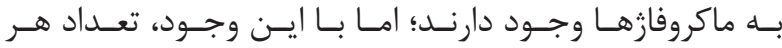

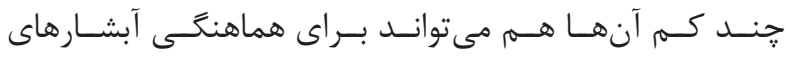

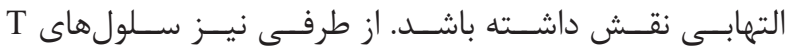

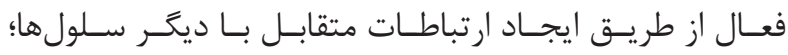

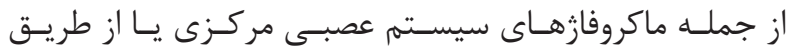

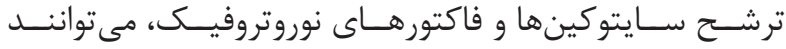

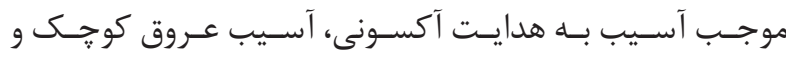

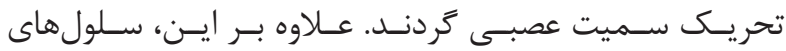

نوتروفيلها و ماكروفازها در آسيب نخاعى

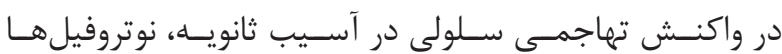

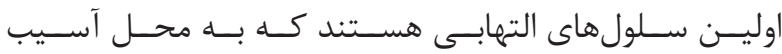

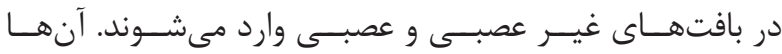

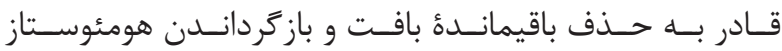

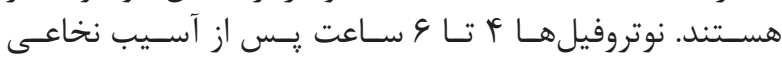

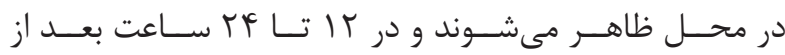

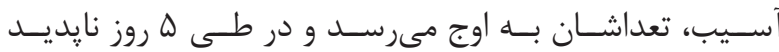

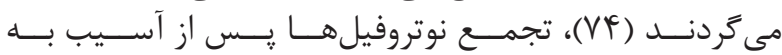

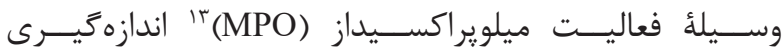

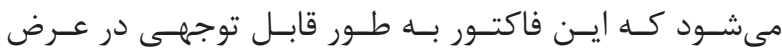

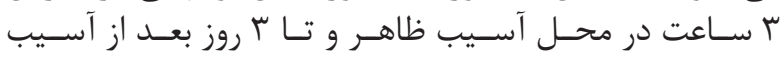

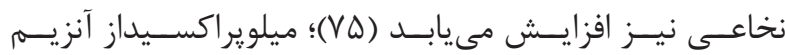

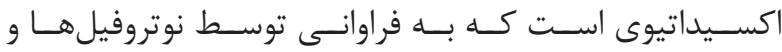

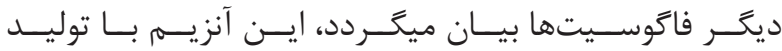

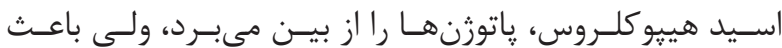

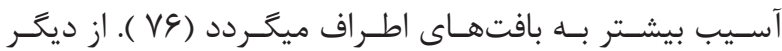

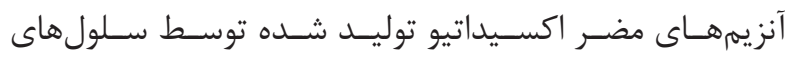

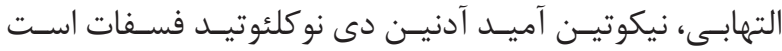

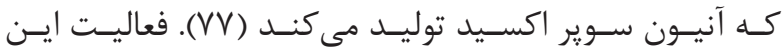

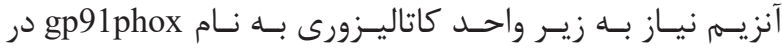

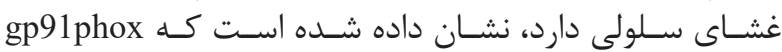

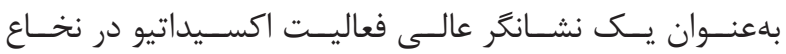
مــوش صحرايسى عمـل مى كنــد (VA).

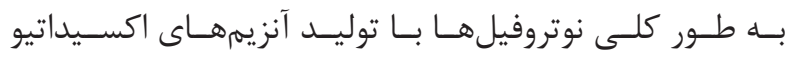

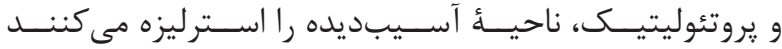

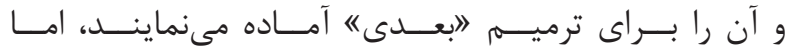

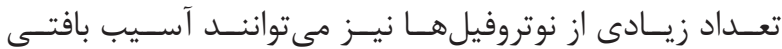

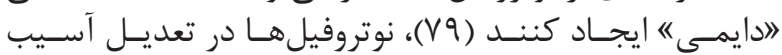

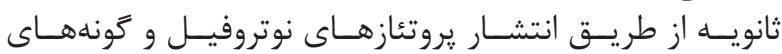

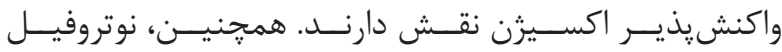

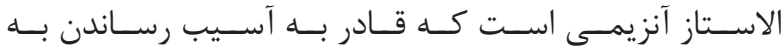

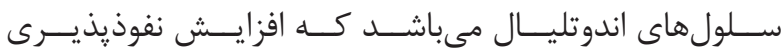

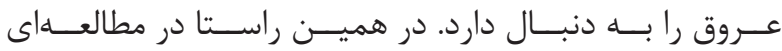

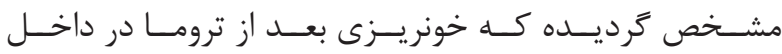

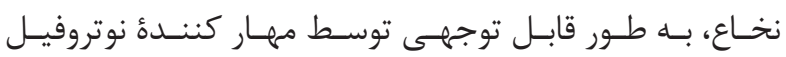

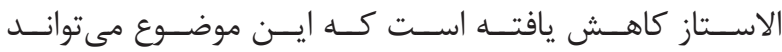

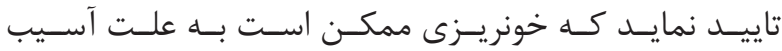

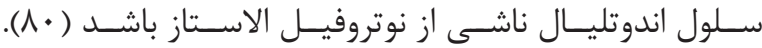

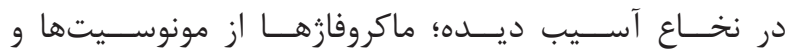

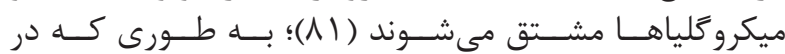

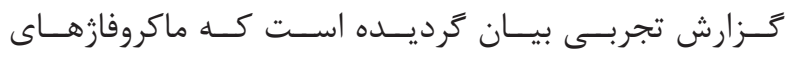

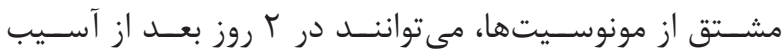

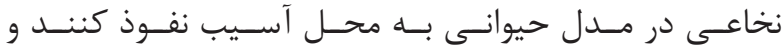

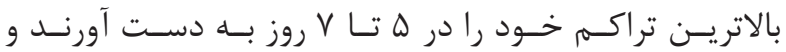

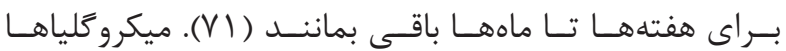


جوانهزنــى آكسـونى اشــاره كــرد (با9).

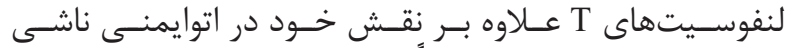

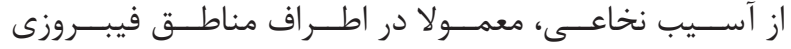

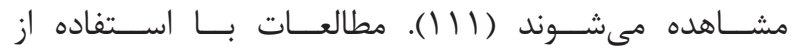

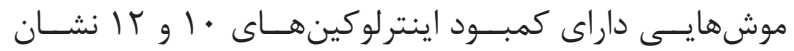

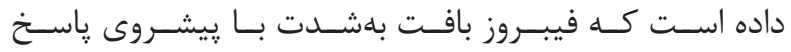

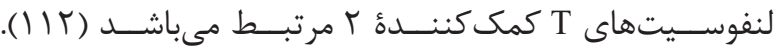

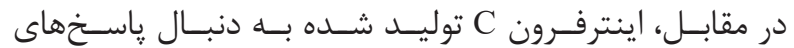

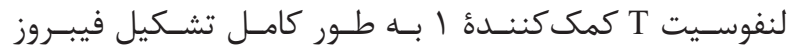

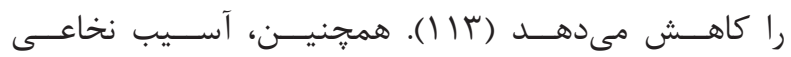

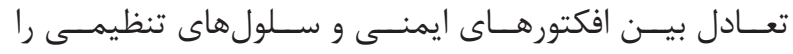

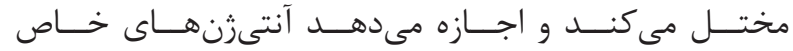

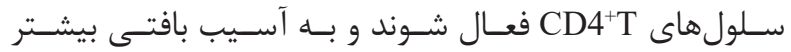

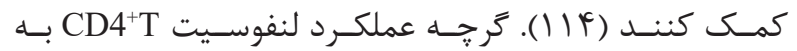

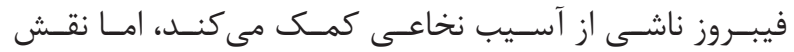

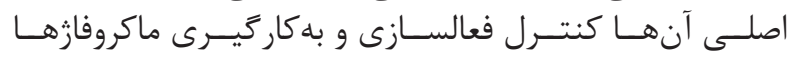

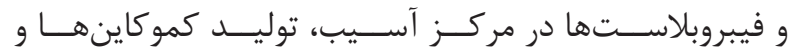

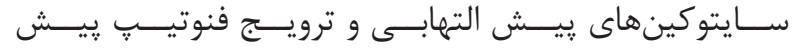

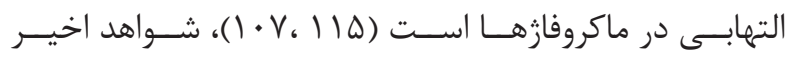

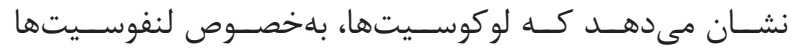

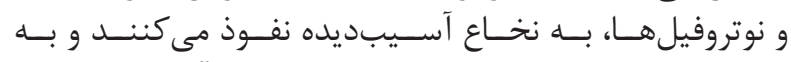

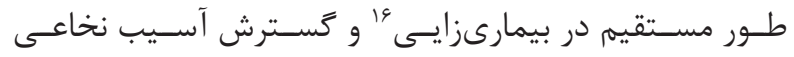

دخالـت مى منماينــــ (1) (1).

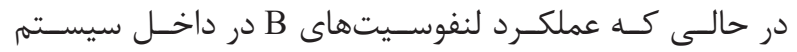

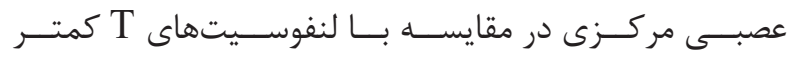

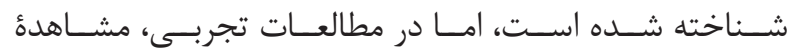

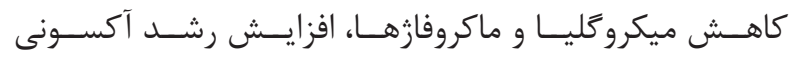

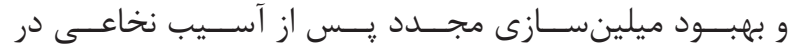

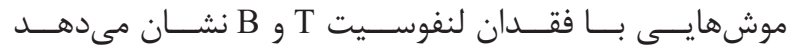

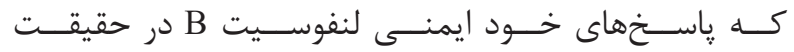

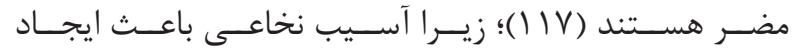

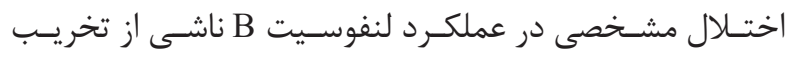

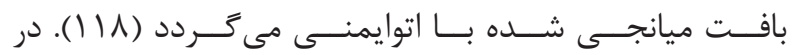

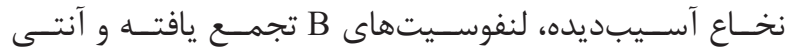

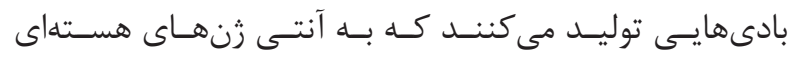

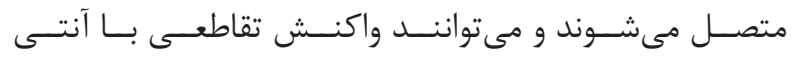

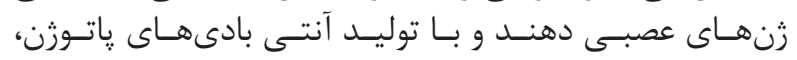

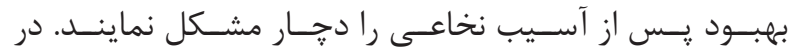

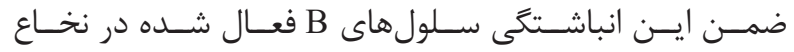

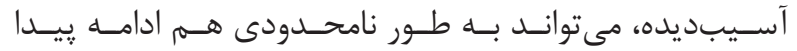

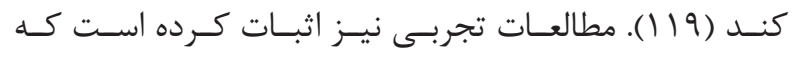

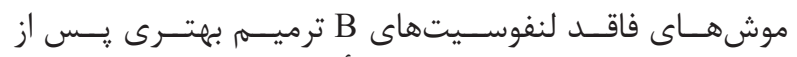

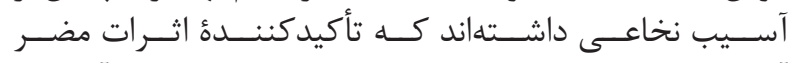

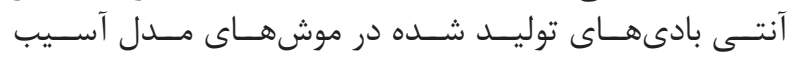

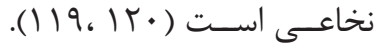

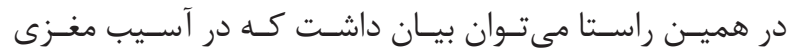

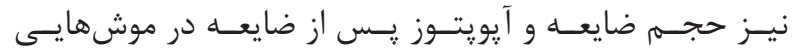

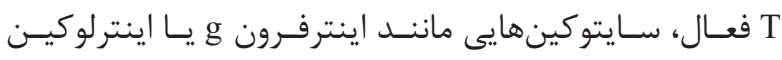

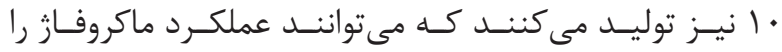

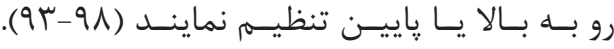

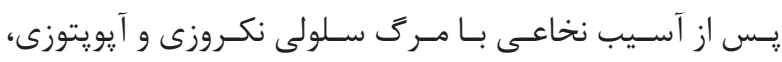

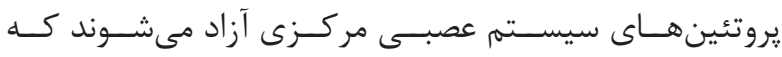

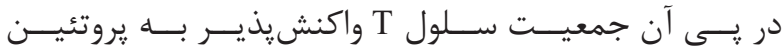

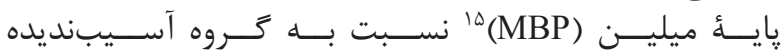

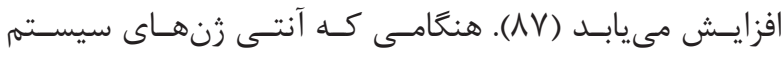

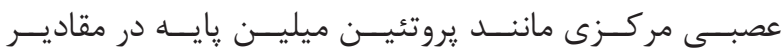

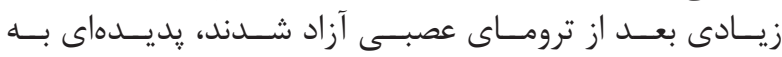

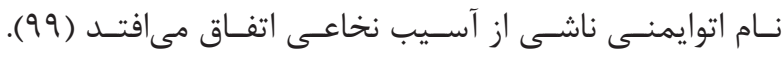

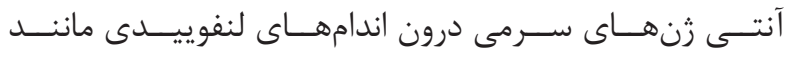

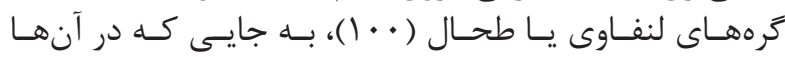

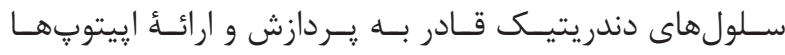

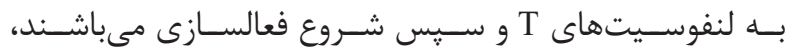

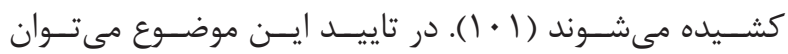

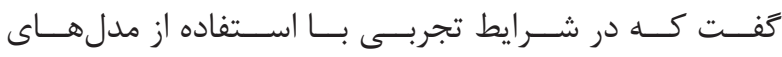

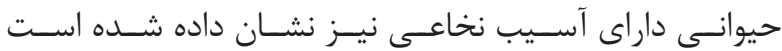

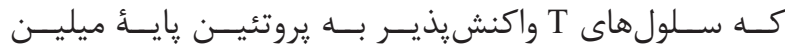

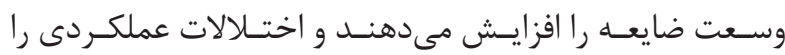

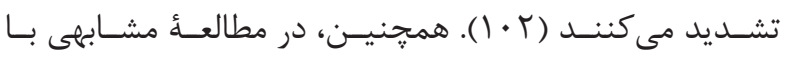

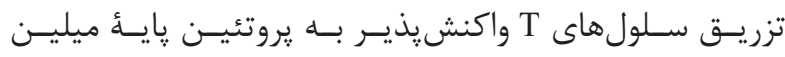

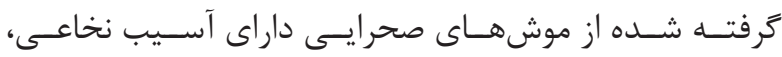

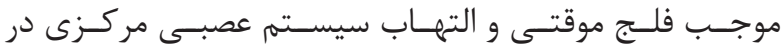

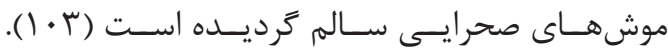

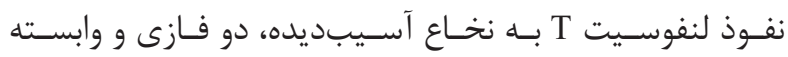

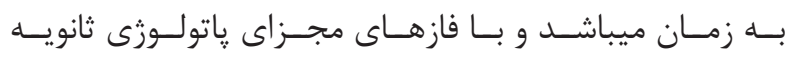

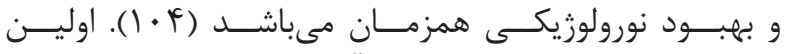

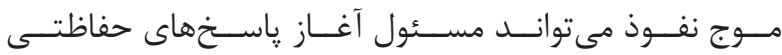

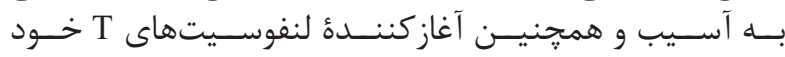

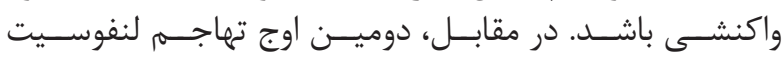

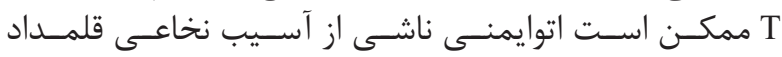

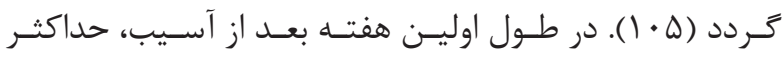

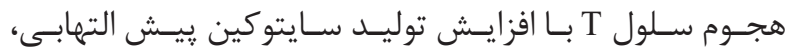

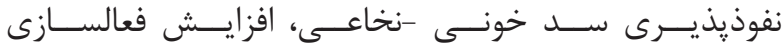

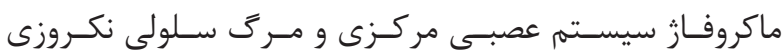

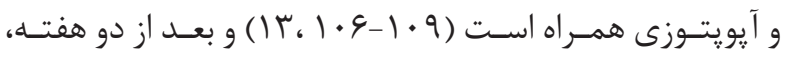

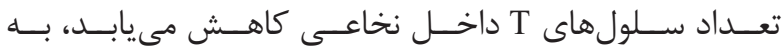

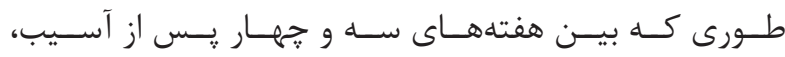

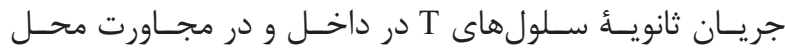

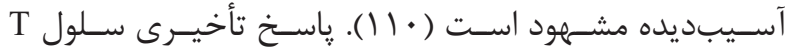

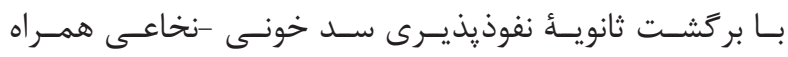

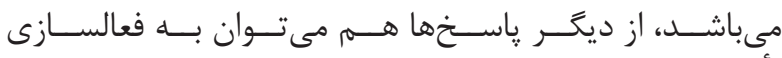

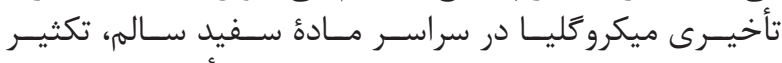

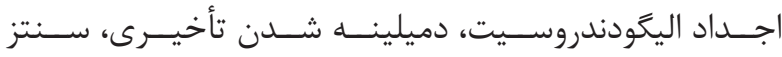

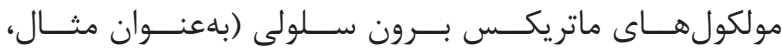

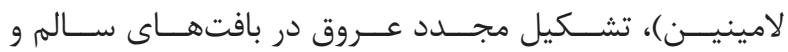

\footnotetext{
${ }^{15}$ Myelin basic protein

${ }^{16}$ Pathogenicity
} 


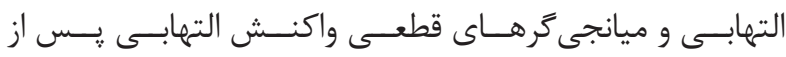

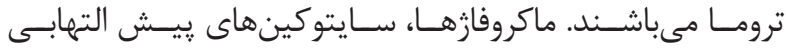

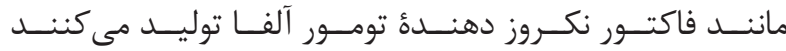

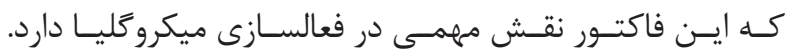

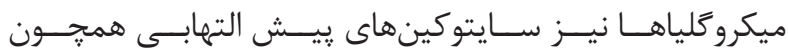

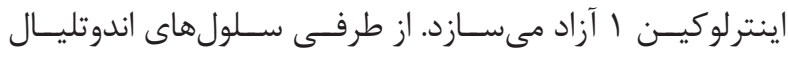

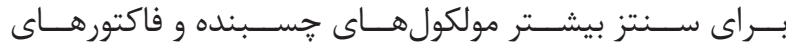

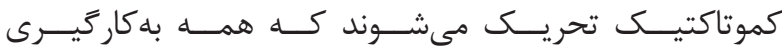

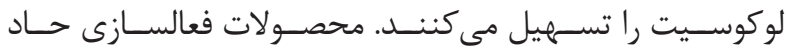

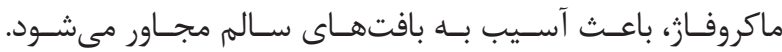

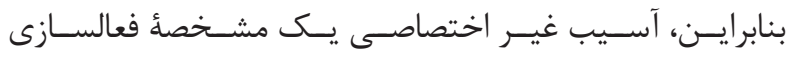

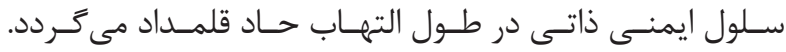

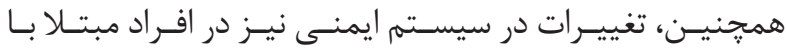

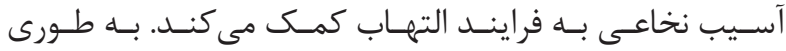

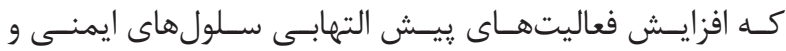

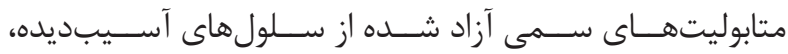

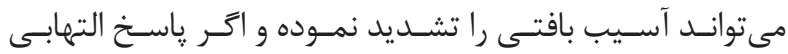

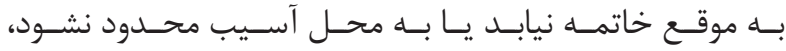

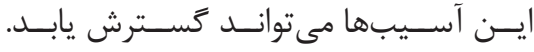

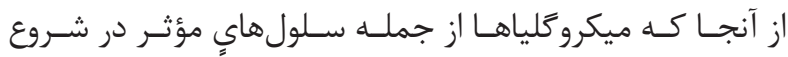

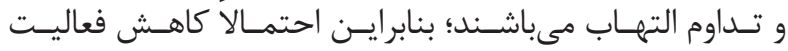

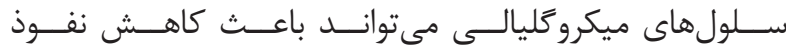

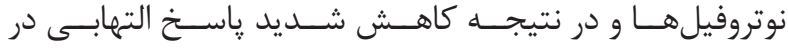

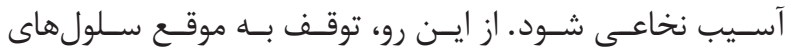

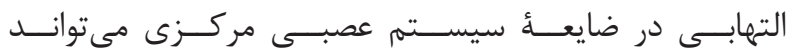

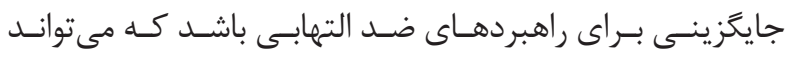

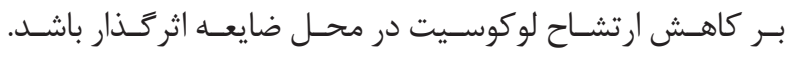

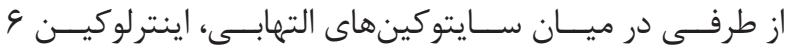

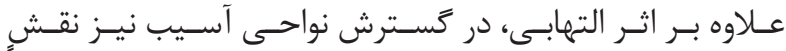

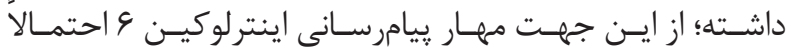

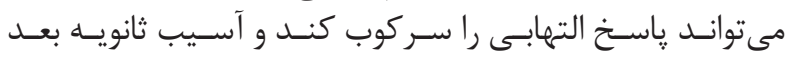

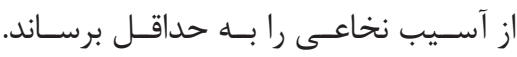

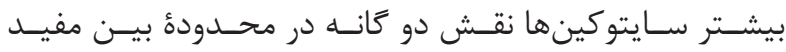

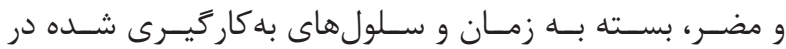

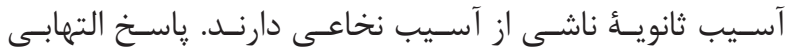

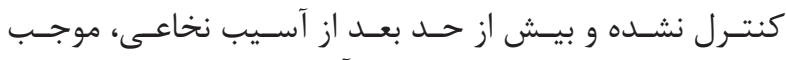

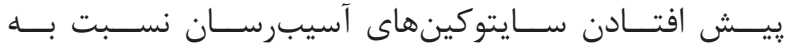

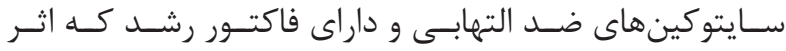

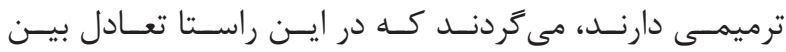

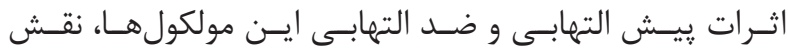

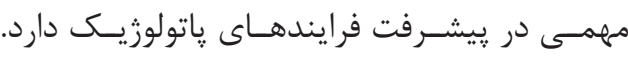

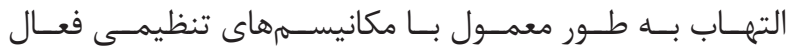

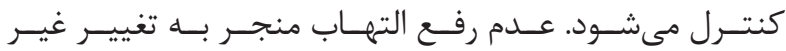

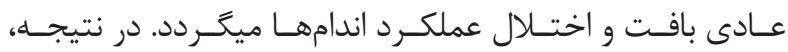

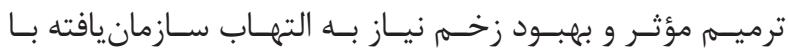

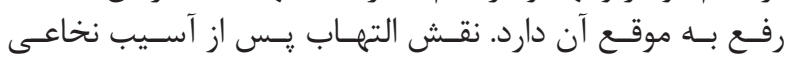

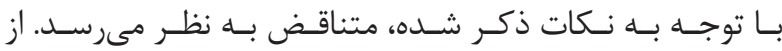

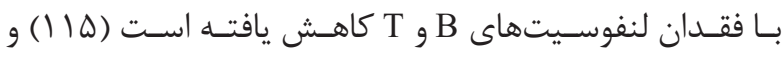

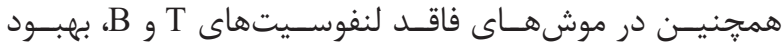

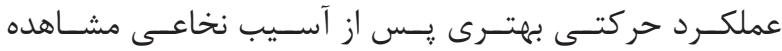

كرديـده است (IV)

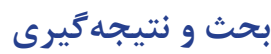

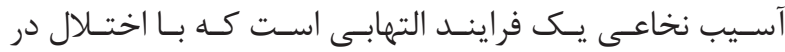

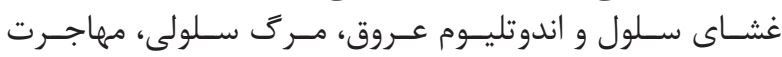

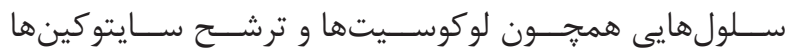

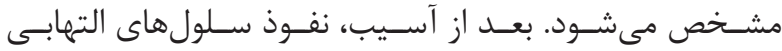

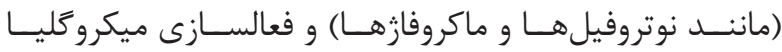

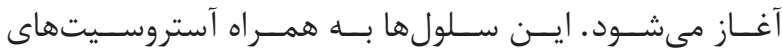

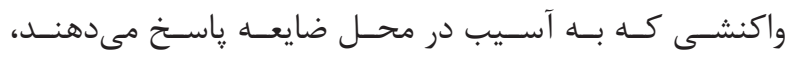

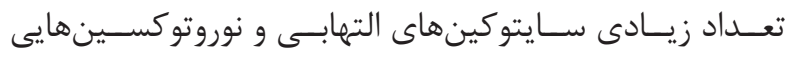

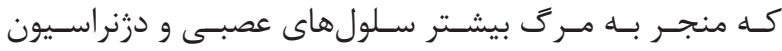

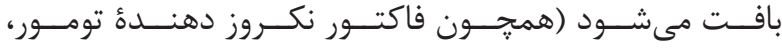

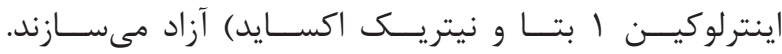

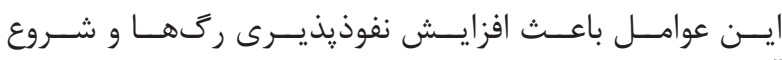

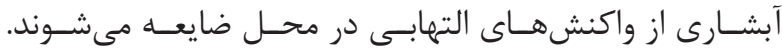

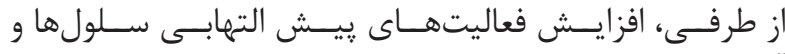

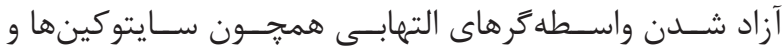

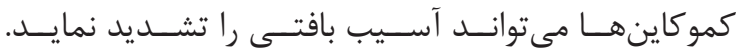

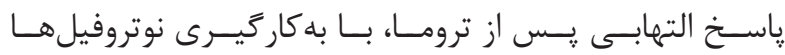

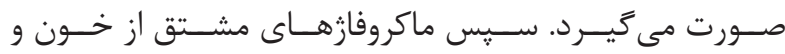

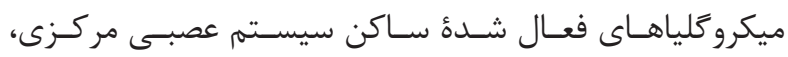

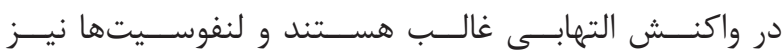

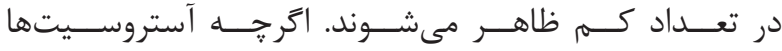

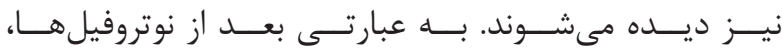

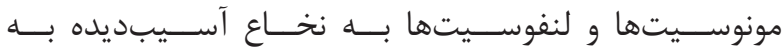

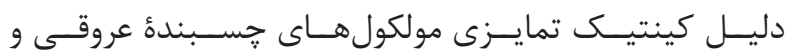

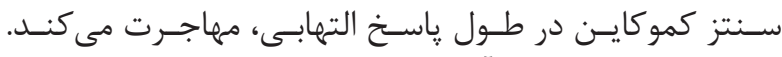

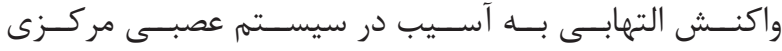

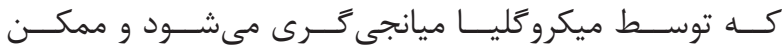

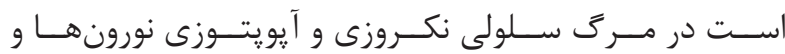

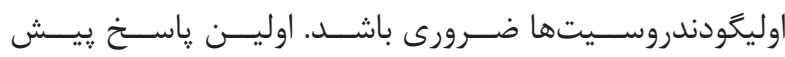

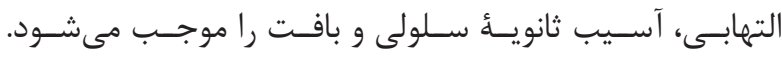

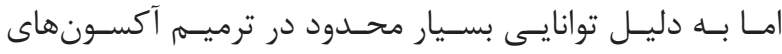

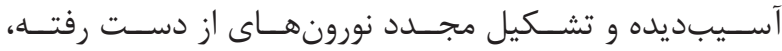

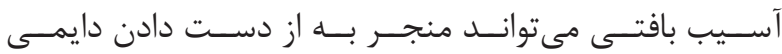

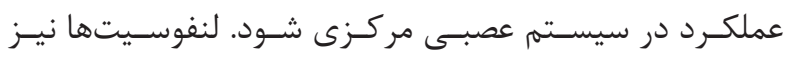

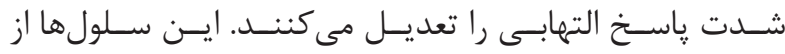

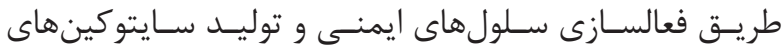

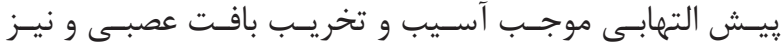

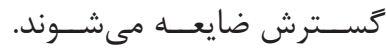

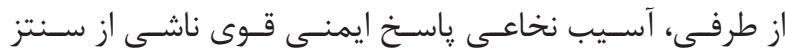

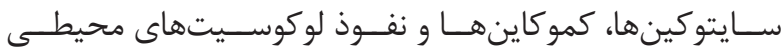

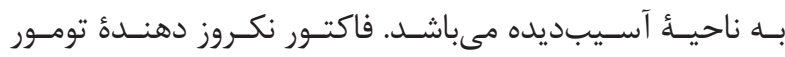

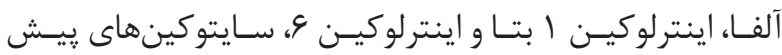




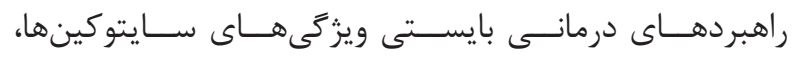

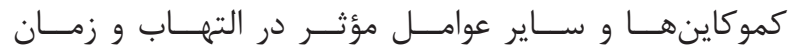

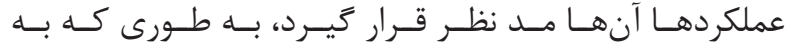

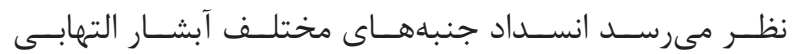

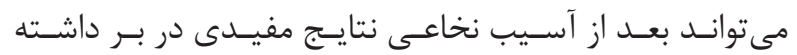

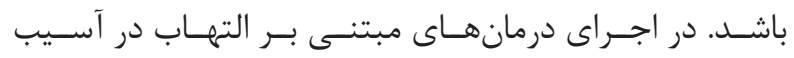

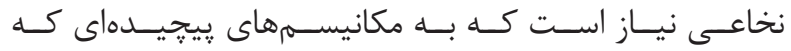

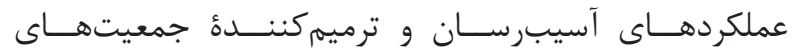

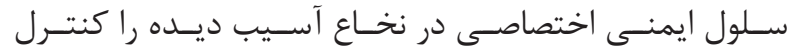

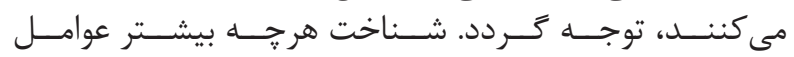

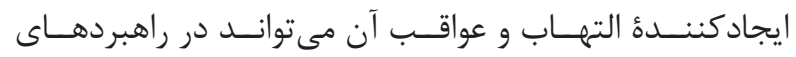

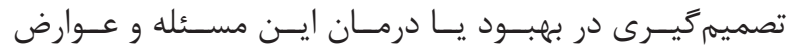

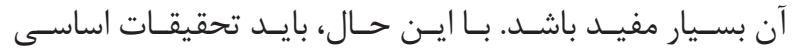

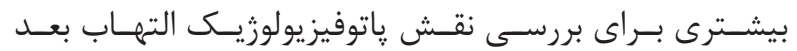

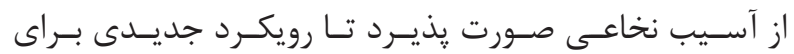

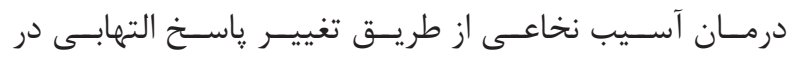
آســيب نخاعسى بيشــــهاد شــود.

1. Gashmardi N, Mehrabani D, Hosseini S, Edalatmanesh $\mathrm{M}$, Khodabandeh $\mathrm{Z}$. The healing of bone marrowderived stem cells on motor functions in acute spinal cord injury of mice. Armaghane Danesh. 2016; 21(7): $669-81$.

2. Ahuja CS, Nori S, Tetreault L, Wilson J, Kwon B, Harrop J, et al. Traumatic spinal cord injury-repair and regeneration. Neurosurgery. 2017; 80(3S): S9-S22.

3. Spitzbarth I, Bock P, Haist V, Stein VM, Tipold A, Wewetzer K, et al. Prominent microglial activation in the early proinflammatory immune response in naturally occurring canine spinal cord injury. J Neuropathol Exp Neurol. 2011; 70(8): 703-14.

4. Singh A, Tetreault L, Kalsi-Ryan S, Nouri A, Fehlings MG. Global prevalence and incidence of traumatic spinal cord injury. Clin Epidemiol. 2014; 6: 309-31.

5. Jazayeri SB, Ataeepour M, Rabiee H, Motevalian SA, Saadat S, Vaccaro AR, et al. Prevalence of spinal cord injury in Iran: a 3-source capture-recapture study. Neuroepidemiology. 2015; 45(1): 28-33.

6. Rahimi-Movaghar V, Saadat S, Rasouli MR, Ganji S, Ghahramani M, Zarei MR, et al. Prevalence of spinal cord injury in Tehran, Iran. J Spinal Cord Med. 2009; 32(4): 428-31.

7. Esteghamat Hanzai SS, Moghadami Monaghi S, Gorji A. prevalence of overweight and obesity in patients with spinal cord injury. Shefaye Khatam. 2015; 3(1): 65-70.

8. Oyinbo CA. Secondary injury mechanisms in traumatic

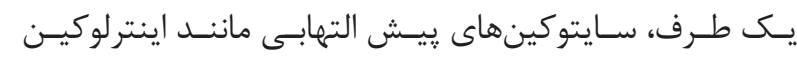

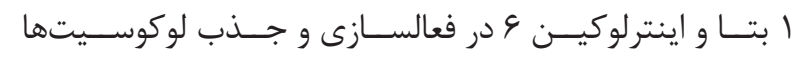

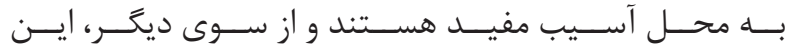

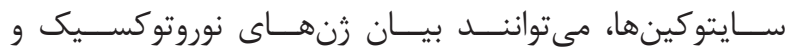

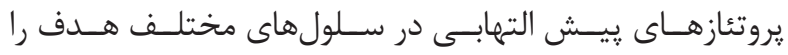

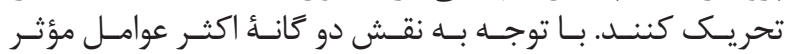

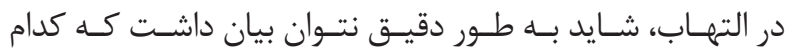

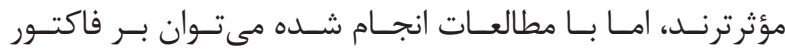

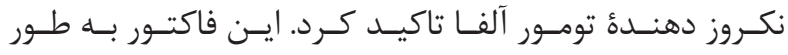

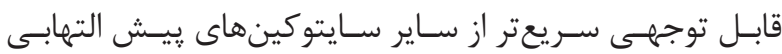

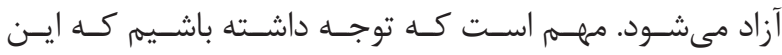

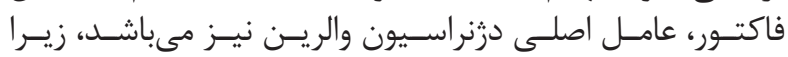

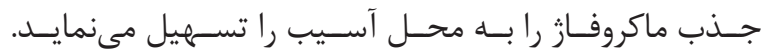

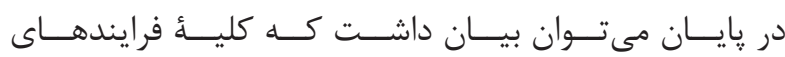

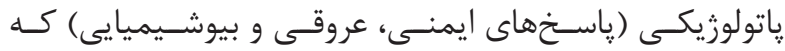

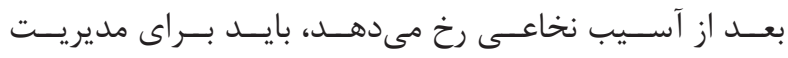

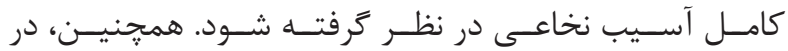

منابع

spinal cord injury: a nugget of this multiply cascade. Acta Neurobiol Exp (Wars). 2011; 71(2): 281-99.

9. Tator $\mathrm{CH}$, Koyanagi I. Vascular mechanisms in the pathophysiology of human spinal cord injury. J Neurosurg. 1997; 86(3): 483-92.

10. Kwon BK, Tetzlaff W, Grauer JN, Beiner J, Vaccaro AR. Pathophysiology and pharmacologic treatment of acute spinal cord injury. Spine J. 2004; 4(4): 451-64.

11. Dalbayrak S, Yaman O, Yılmaz T. Current and future surgery strategies for spinal cord injuries. World $\mathrm{J}$ Orthop. 2015; 6(1): 34-41.

12. Profyris C, Cheema SS, Zang D, Azari MF, Boyle K, Petratos S. Degenerative and regenerative mechanisms governing spinal cord injury. Neurobiol Dis. 2004; 15(3): 415-36.

13. Gashmardi N, Hosseini SE, Mehrabani D, Edalatmanesh MA, Khodabandeh Z. Impacts of Bone marrow stem cells on caspase-3 levels after spinal cord injury in mice. IJMS. 2017; 42(6): 593.

14. Popovich PG, Jones TB. Manipulating neuroinflammatory reactions in the injured spinal cord: back to basics. Trends Pharmacol Sci. 2003; 24(1): 13-7.

15. David S, Greenhalgh AD, López-Vales R. Role of phospholipase A $2 \mathrm{~s}$ and lipid mediators in secondary damage after spinal cord injury. Cell Tissue Res. 2012; 349(1): 249-67.

16. Silver J, Schwab ME, Popovich PG. Central nervous 
system regenerative failure: role of oligodendrocytes, astrocytes, and microglia. Cold Spring Harb Perspect Biol. 2015; 7(3): a020602.

17. Bastien D, Landete VB, Lessard M, Vallières $N$, Champagne M, Takashima A, et al. IL- $1 \alpha$ gene deletion protects oligodendrocytes after spinal cord injury through upregulation of the survival factor Tox3. J Neurosci. 2015; 35(30): 10715-30.

18. Bartholdi D, Schwab ME. Expression of proinflammatory cytokine and chemokine mRNA upon experimental spinal cord injury in mouse: An in situ hybridization study. Eur J Neurosci. 1997; 9(7): 1422-38.

19. Casha S, Yu W, Fehlings M. Oligodendroglial apoptosis occurs along degenerating axons and is associated with FAS and p75 expression following spinal cord injury in the rat. Neuroscience. 2001; 103(1): 203-18.

20. Beattie MS. Inflammation and apoptosis: linked therapeutic targets in spinal cord injury. Trends Mol Med. 2004; 10(12): 580-3.

21. Beattie EC, Stellwagen D, Morishita W, Bresnahan JC, Ha BK, Von Zastrow M, et al. Control of synaptic strength by glial TNFa. Science. 2002; 295(5563): 2282-5.

22. Popovich PG. Immunological regulation of neuronal degeneration and regeneration in the injured spinal cord. Prog Brain Res. 2000; 128: 43-58.

23. Shen LF, Cheng H, Tsai MC, Kuo HS, Chak KF. PAL31 may play an important role as inflammatory modulator in the repair process of the spinal cord injury rat. J Neurochemistry. 2009; 108(5): 1187-97.

24. Donnelly DJ, Popovich PG. Inflammation and its role in neuroprotection, axonal regeneration and functional recovery after spinal cord injury. Exp Neurol. 2008; 209(2): 378-88.

25. DiSabato DJ, Quan N, Godbout JP. Neuroinflammation: the devil is in the details. J Neurochem. 2016; 139(S2): 136-53.

26. Mabon PJ, Weaver LC, Dekaban GA. Inhibition of monocyte/macrophage migration to a spinal cord injury site by an antibody to the integrin $\alpha \mathrm{D}$ : a potential new anti-inflammatory treatment. Exp Neurol. 2000; 166(1): $52-64$.

27. Stoll G, Jander S, Schroeter M. Detrimental and beneficial effects of injury-induced inflammation and cytokine expression in the nervous system. Adv Exp
Med Biol. 2002; 513: 87-113.

28. Gashmardi N, Edalatmanesh MA. Perspective on cellular and molecular mechanisms of mesenchymal stem cell transplantation in spinal cord injuries. Shefaye Khatam. 2016; 5(3): 51-61.

29. Husemann J, Loike JD, Anankov R, Febbraio M, Silverstein SC. Scavenger receptors in neurobiology and neuropathology: their role on microglia and other cells of the nervous system. Glia. 2002; 40(2): 195-205.

30. Chen C-J, Kono H, Golenbock D, Reed G, Akira S, Rock KL. Identification of a key pathway required for the sterile inflammatory response triggered by dying cells. Nat Med. 2007; 13(7): 851.

31. Gill S, Wight TN, Frevert CW. Proteoglycans: key regulators of pulmonary inflammation and the innate immune response to lung infection. Anat Rec. 2010; 293(6): 968-81.

32. Gaudet AD, Popovich PG. Extracellular matrix regulation of inflammation in the healthy and injured spinal cord. Exp Neurol. 2014; 258: 24-34.

33. Pineau I, Sun L, Bastien D, Lacroix S. Astrocytes initiate inflammation in the injured mouse spinal cord by promoting the entry of neutrophils and inflammatory monocytes in an IL-1 receptor/MyD88-dependent fashion. Brain Behav Immun. 2010; 24(4): 540-53.

34. Gashmardi N, Mehrabani D, Khodabandeh Z, Hosseini SM. Effect of Bone marrow-derived mesenchymal stem cells on changes of serum levels of tnf- $\alpha$ and locomotor function after spinal cord injury in mice. J Med Sci. 2016; 16(1-2): 16-24.

35. Saiwai H, Ohkawa Y, Yamada H, Kumamaru H, Harada A, Okano H, et al. The LTB4-BLT1 axis mediates neutrophil infiltration and secondary injury in experimental spinal cord injury. Am J Pathol. 2010; 176(5): 2352-66.

36. Kumamaru H, Saiwai H, Ohkawa Y, Yamada H, Iwamoto Y, Okada S. Age-related differences in cellular and molecular profiles of inflammatory responses after spinal cord injury. J Cell Physiol. 2012; 227(4): 1335-46.

37. Letellier E, Kumar S, Sancho-Martinez I, Krauth S, Funke-Kaiser A, Laudenklos S, et al. CD95-ligand on peripheral myeloid cells activates Syk kinase to trigger their recruitment to the inflammatory site. Immunity. 2010; 32(2): 240-52.

38. Vallières N, Berard JL, David S, Lacroix S. Systemic injections of lipopolysaccharide accelerates myelin 


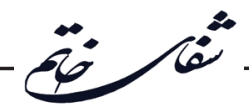

phagocytosis during Wallerian degeneration in the injured mouse spinal cord. Glia. 2006; 53(1): 103-13.

39. Hanisch UK. Microglia as a source and target of cytokines. Glia. 2002; 40(2): 140-55.

40. Wanner IB, Anderson MA, Song B, Levine J, Fernandez A, Gray-Thompson Z, et al. Glial scar borders are formed by newly proliferated, elongated astrocytes that interact to corral inflammatory and fibrotic cells via STAT3-dependent mechanisms after spinal cord injury. J Neuroscience. 2013; 33(31): 12870-86.

41. Vafaee F, Hosseini M, Hassanzadeh Z, Edalatmanesh MA, Sadeghnia HR, Seghatoleslam M, et al. The effects of Nigella sativa hydro-alcoholic extract on memory and brain tissues oxidative damage after repeated seizures in rats. Iran J Pharm Res. 2015; 14(2): 547-57.

42. Oppenheim JJ, Yang D. Alarmins: chemotactic activators of immune responses. Curr Opin Immunol. 2005; 17(4): 359-65.

43. Ramesh G, MacLean AG, Philipp MT. Cytokines and chemokines at the crossroads of neuroinflammation, neurodegeneration, and neuropathic pain. Mediators Inflamm. 2013; 2013(480739): 1-21.

44. Turner MD, Nedjai B, Hurst T, Pennington DJ. Cytokines and chemokines: at the crossroads of cell signalling and inflammatory disease. Biochim Biophys Acta. 2014; 1843(11): 2563-82.

45. Dinarello CA. Historical insights into cytokines. Eur J Immunol. 2007; 37(S1): 34-45.

46. Jones T, McDaniel E, Popovich P. Inflammatorymediated injury and repair in the traumatically injured spinal cord. Curr Pharm Des. 2005; 11(10): 1223-36.

47. Ulndreaj A, Chio JC, Ahuja CS, Fehlings MG. Modulating the immune response in spinal cord injury. Expert Rev Neurother. 2016; 16(10): 1127-9.

48. Dinarello CA. Immunological and inflammatory functions of the interleukin-1 family. Annu Rev Immunol. 2009; 27: 519-50.

49. Bethea JR. Spinal cord injury-induced inflammation: a dual-edged sword. Prog Brain Res. 2000; 128: 33-42.

50. Bastien D, Landete VB, Lessard M, Vallières N, Champagne M, Takashima A, et al. IL- $1 \alpha$ gene deletion protects oligodendrocytes after spinal cord injury through upregulation of the survival factor Tox3. J Neurosci. 2015; 35(30): 10715-30.

51. Yang L, Blumbergs PC, Jones NR, Manavis J,
Sarvestani GT, Ghabriel MN. Early expression and cellular localization of proinflammatory cytokines interleukin-1 $\beta$, interleukin-6, and tumor necrosis factor- $\alpha$ in human traumatic spinal cord injury. Spine. 2004; 29(9): 966-71.

52. Zhou X, He X, Ren Y. Function of microglia and macrophages in secondary damage after spinal cord injury. Neural Regen Res. 2014; 9(20): 1787-95.

53. Blesch A, Tuszynski MH. Transient growth factor delivery sustains regenerated axons after spinal cord injury. J Neurosci. 2007; 27(39): 10535-45.

54. Baziyar Y, Edalatmanesh MA, Hosseini SA, Zar A. The effects of endurance training and gallic acid on bdnf and tnf-a in male rats with Alzheimer. J Appl Biomech. 2016; 5(4): 45-54.

55. Pan W, Kastin AJ, Bell RL, Olson RD. Upregulation of tumor necrosis factor $\alpha$ transport across the bloodbrain barrier after acute compressive spinal cord injury. J Neurosci. 1999; 19(9): 3649-55.

56. Bethea JR, Nagashima H, Acosta MC, Briceno C, Gomez F, Marcillo AE, et al. Systemically administered interleukin-10 reduces tumor necrosis factor-alpha production and significantly improves functional recovery following traumatic spinal cord injury in rats. J Neurotrauma. 1999; 16(10): 851-63.

57. McPhail LT, Oschipok LW, Liu J, Tetzlaff W. Both positive and negative factors regulate gene expression following chronic facial nerve resection. Exp Neurol. 2005; 195(1): 199-207.

58. Probert L, Eugster H-P, Akassoglou K, Bauer J, Frei $\mathrm{K}$, Lassmann $\mathrm{H}$, et al. TNFR1 signalling is critical for the development of demyelination and the limitation of T-cell responses during immune-mediated CNS disease. Brain. 2000; 123(10): 2005-19.

59. Sorkin L, Xiao W-H, Wagner R, Myers R. Tumour necrosis factor- $\alpha$ induces ectopic activity in nociceptive primary afferent fibres. Neuroscience. 1997; 81(1): 255562.

60. Lavine SD, Hofman FM, Zlokovic BV. Circulating antibody against tumor necrosis factor-alpha protects rat brain from reperfusion injury. J Cereb Blood Flow Metab. 1998; 18(1): 52-8.

61. Barger SW, Hörster D, Furukawa K, Goodman Y, Krieglstein J, Mattson MP. Tumor necrosis factors alpha and beta protect neurons against amyloid betapeptide toxicity: evidence for involvement of a kappa B-binding factor and attenuation of peroxide and $\mathrm{Ca} 2+$ accumulation. Proc Natl Acad Sci U S A. 1995; 92(20): 9328-32. 
62. Lazarov-Spiegler O, Rapalino O, Agranov G, Schwartz M. Restricted inflammatory reaction in the CNS: a key impediment to axonal regeneration? Mol Med Today. 1998; 4(8): 337-42.

63. Okada S, Nakamura M, Renault-Mihara F, Mukaino M, Saiwai H, Toyama Y, et al. The role of cytokine signaling in pathophysiology for spinal cord injury. Inflamm Regen. 2008; 28(5): 440-6.

64. Trivedi A, Olivas AD, Noble-Haeusslein LJ. Inflammation and spinal cord injury: infiltrating leukocytes as determinants of injury and repair processes. Clin Neurosci Res. 2006; 6(5): 283-92.

65. Pineau I, Lacroix S. Proinflammatory cytokine synthesis in the injured mouse spinal cord: multiphasic expression pattern and identification of the cell types involved. J Comp Neurol. 2007; 500(2): 267-85.

66. Van Wagoner NJ, Benveniste EN. Interleukin-6 expression and regulation in astrocytes. J Neuroimmunol. 1999; 100(1-2): 124-39.

67. Lacroix S, Chang L, Rose-John S, Tuszynski MH. Delivery of hyper-interleukin-6 to the injured spinal cord increases neutrophil and macrophage infiltration and inhibits axonal growth. J Comp Neurol. 2002; 454(3): 213-28.

68. David S, López-Vales R, Yong VW. Harmful and beneficial effects of inflammation after spinal cord injury: potential therapeutic implications. Handb Clin Neurol. 2012; 109; 485-502.

69. McTigue DM, Tani M, Krivacic K, Chernosky A, Kelner GS, Maciejewski D, et al. Selective chemokine mRNA accumulation in the rat spinal cord after contusion injury. J Neurosci Res. 1998; 53(3): 368-76.

70. Ghirnikar R, Lee Y, Eng L. Chemokine antagonist infusion attenuates cellular infiltration following spinal cord contusion injury in rat. J Neurosci Res. 2000; 59(1): 63-73.

71. Popovich PG, Wei P, Stokes BT. Cellular inflammatory response after spinal cord injury in sprague-dawley and lewis rats. J Comp Neurol. 1997; 377(3): 443-64

72. Rice T, Larsen J, Rivest S, Yong VW. Characterization of the early neuroinflammation after spinal cord injury in mice. J Neuropathol Exp Neurol. 2007; 66(3): 184-95.

73. Lee Y, Shih K, Bao P, Ghirnikar R, Eng L. Cytokine chemokine expression in contused rat spinal cord. Neurochem Int. 2000; 36(4-5): 417-25.

74. Carlson SL, Parrish ME, Springer JE, Doty K,
Dossett L. Acute inflammatory response in spinal cord following impact injury. Exp Neurol. 1998; 151(1): 7788 .

75. Chatzipanteli K, Yanagawa Y, Marcillo AE, Kraydieh S, Yezierski RP, Dietrich WD. Posttraumatic hypothermia reduces polymorphonuclear leukocyte accumulation following spinal cord injury in rats. J Neurotrauma. 2000; 17(4): 321-32.

76. Bao F, Chen Y, Weaver L. Early anti-inflammatory treatment reduces lipid peroxidation and nitrotyrosine after spinal cord injury in rats. J Neurochem. 2004; 88(6): $1335-44$

77. Brandes RP, Kreuzer J. Vascular NADPH oxidases: molecular mechanisms of activation. Cardiovasc Res. 2005; 65(1): 16-27.

78. Bao F, Dekaban GA, Weaver LC. Anti-CD11d antibody treatment reduces free radical formation and cell death in the injured spinal cord of rats. J Neurochem. 2005; 94(5): 1361-73.

79. Taoka Y, Okajima K, Uchiba M, Murakami K, Kushimoto S, Johno M, et al. Role of neutrophils in spinal cord injury in the rat. Neuroscience. 1997; 79(4): 1177-82.

80. Taoka Y, Okajima K. Role of leukocytes in spinal cord injury in rats. J Neurotrauma. 2000; 17(3): 219-29.

81. Popovich PG, Guan Z, Wei P, Huitinga I, van Rooijen N, Stokes BT. Depletion of hematogenous macrophages promotes partial hindlimb recovery and neuroanatomical repair after experimental spinal cord injury. Exp Neurol. 1999; 158(2): 351-65.

82. Popovich P, Guan Z, McGaughy V, Fisher L, Hickey $\mathrm{W}$, Basso D. The neuropathological and behavioral consequences of intraspinal microglial/macrophage activation. J Neuropathol Exp Neurol. 2002; 61(7): 623-33.

83. Zhang Z, Krebs CJ, Guth L. Experimental analysis of progressive necrosis after spinal cord trauma in the rat: etiological role of the inflammatory response. Exp Neurol. 1997; 143(1): 141-52.

84. Ghirnikar R, Lee Y, He T, Eng L. Chemokine expression in rat stab wound brain injury. J Neurosci Res. 1996; 46(6): 727-33.

85. Schwab ME, Bartholdi D. Degeneration and regeneration of axons in the lesioned spinal cord. Physiol Rev. 1996; 76(2): 319-70.

86. David S, Kroner A. Repertoire of microglial and macrophage responses after spinal cord injury. Nat Rev 


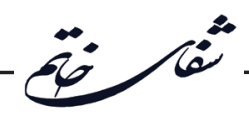

Neurosci. 2011; 12(7): 388-99.

87. Jones TB, Hart RP, Popovich PG. Molecular control of physiological and pathological T-cell recruitment after mouse spinal cord injury. J Neurosci. 2005; 25(28): 6576-83.

88. Popovich PG. Immunological regulation of neuronal degeneration and regeneration in the injured spinal cord. Prog Brain Res. 2000; 128: 43-58.

89. Hausmann O. Post-traumatic inflammation following spinal cord injury. Spinal Cord. 2003; 41(7): 369-78.

90. Bessis A, Béchade C, Bernard D, Roumier A. Microglial control of neuronal death and synaptic properties. Glia. 2007; 55(3): 233-8.

91. Butovsky O, Ziv Y, Schwartz A, Landa G, Talpalar AE, Pluchino S, et al. Microglia activated by IL-4 or IFN- $\gamma$ differentially induce neurogenesis and oligodendrogenesis from adult stem/progenitor cells. Mol Cell Neurosci. 2006; 31(1): 149-60.

92. Ponomarev ED, Maresz K, Tan Y, Dittel BN. CNSderived interleukin-4 is essential for the regulation of autoimmune inflammation and induces a state of alternative activation in microglial cells. J Neurosci. 2007; 27(40): 10714-21.

93. Satzer D, Miller C, Maxon J, Voth J, DiBartolomeo $\mathrm{C}$, Mahoney R, et al. T cell deficiency in spinal cord injury: altered locomotor recovery and whole-genome transcriptional analysis. BMC Neuroscience. 2015; 16(1): 74-87.

94. Lodge PA, Sriram S. Regulation of microglial activation by TGF- $\beta$, IL-10, and CSF-1. Curr Pharm Des. 1996; 60(4): 502-8.

95. Naparstek Y, Cohen IR, Fuks Z, Vlodavsky I. Activated $\mathrm{T}$ lymphocytes produce a matrix-degrading heparan sulphate endoglycosidase. Nature. 1984; 310(5974): 241-4.

96. Anwar MA, Al Shehabi TS, Eid AH. Inflammogenesis of secondary spinal cord injury. Front Cell Neurosci. 2016; 10(98): 1-24.

97. Ishii H, Jin X, Ueno M, Tanabe S, Kubo T, Serada S, et al. Adoptive transfer of Th1-conditioned lymphocytes promotes axonal remodeling and functional recovery after spinal cord injury. Cell Death Dis. 2012; 3(8): e363.

98. Held KS, LaneTE. Spinal cord injury, immunodepression, and antigenic challenge. Semin Immunol. 2014; 26(5): 415-20.
99. Ankeny DP, Popovich PG. Mechanisms and implications of adaptive immune responses after traumatic spinal cord injury. Neuroscience. 2009; 158(3): 1112-21.

100. Ling C, Sandor M, Fabry Z. In situ processing and distribution of intracerebrally injected OVA in the CNS. J Neuroimmunol. 2003; 141(1): 90-8.

101. Karman J, Ling C, Sandor M, Fabry Z. Initiation of immune responses in brain is promoted by local dendritic cells. J Immunol. 2004; 173(4): 2353-61.

102. Lü H-Z, Xu L, Zou J, Wang Y-X, Ma Z-W, Xu $\mathrm{X}-\mathrm{M}$, et al. Effects of autoimmunity on recovery of function in adult rats following spinal cord injury. Brain Behav Immun. 2008; 22(8): 1217-30.

103. Popovich PG, Horner PJ, Mullin BB, Stokes BT. A quantitative spatial analysis of the blood-spinal cord barrier: I. Permeability changes after experimental spinal contusion injury. Exp Neurol. 1996; 142(2): 258-75.

104. Sroga JM, Jones T, Kigerl KA, McGaughy VM, Popovich PG. Rats and mice exhibit distinct inflammatory reactions after spinal cord injury. J Comp Neurol. 2003; 462(2): 223-40.

105. Bowes AL, Yip PK. Modulating inflammatory cell responses to spinal cord injury: all in good time. $\mathrm{J}$ Neurotrauma. 2014; 31(21): 1753-66.

106. Tator CH, Koyanagi I. Vascular mechanisms in the pathophysiology of human spinal cord injury. J Neurosurg. 1997; 86(3): 483-92.

107. Mukhamedshina YO, Akhmetzyanova ER, Martynova EV, Khaiboullina SF, Galieva LR, Rizvanov AA. Systemic and local cytokine profile following spinal cord injury in rats: a Multiplex analysis. Front Neurol. 2017; 8(581): 1-7.

108. Dusart I, Schwab M. Secondary cell death and the inflammatory reaction after dorsal hemisection of the rat spinal cord. Eur J Neurosci. 1994; 6(5): 712-24.

109. Springer JE, Azbill RD, Knapp PE. Activation of the caspase-3 apoptotic cascade in traumatic spinal cord injury. Nat Med. 1999; 5(8): 943-6.

110. Travlos A, Anton HA, Wing PC. Cerebrospinal fluid cell count following spinal cord injury. Arch Phys Med Rehabil. 1994; 75(3): 293-6.

111. Kigerl KA, Mcgaughy VM, Popovich PG. Comparative analysis of lesion development and intraspinal inflammation in four strains of mice following spinal contusion injury. J Comp Neurol. 2006; 
494(4): $\quad 578-94$.

112. Hoffmann KF, Cheever AW, Wynn TA. IL-10 and the dangers of immune polarization: excessive type 1 and type 2 cytokine responses induce distinct forms of lethal immunopathology in murine schistosomiasis. J Immunol. 2000; 164(12): 6406-16.

113. Oldroyd SD, Thomas GL, Gabbiani G, El Nahas AM. Interferon- $\gamma$ inhibits experimental renal fibrosis. Kidney Int. 1999; 56(6): 2116-27.

114. Jones TB. Lymphocytes and autoimmunity after spinal cord injury. Exp Neurol. 2014; 258: 78-90.

115. Fee D, Crumbaugh A, Jacques T, Herdrich B, Sewell D, Auerbach D, et al. Activated/effector CD4+ $T$ cells exacerbate acute damage in the central nervous system following traumatic injury. J Neuroimmunol. 2003; 136(1-2): 54-66.

116. Oropallo MA, Goenka R, Cancro MP. Spinal cord injury impacts B cell production, homeostasis, and activation. Semin Immunol. 2014; 26(5): 421-7.

117. Wu B, Matic D, Djogo N, Szpotowicz E, Schachner M, Jakovcevski I. Improved regeneration after spinal cord injury in mice lacking functional T-and B-lymphocytes. Exp Neurol. 2012; 237(2): 274-85.

118. Ankeny DP, Guan Z, Popovich PG. B cells produce pathogenic antibodies and impair recovery after spinal cord injury in mice. J Clin Invest. 2009; 119(10): 2990-9.

119. Ankeny DP, Lucin KM, Sanders VM, McGaughy VM, Popovich PG. Spinal cord injury triggers systemic autoimmunity: evidence for chronic B lymphocyte activation and lupus-like autoantibody synthesis. J Neurochem. 2006; 99(4): 1073-87.

120. Ankeny DP, Popovich PG. B cells and autoantibodies: complex roles in CNS injury. Trends Immunol. 2010; 31(9): 332-8. 